\title{
Extending a first-principles primary production model to predict wheat yields
}

Article

Accepted Version

Creative Commons: Attribution-Noncommercial-No Derivative Works 4.0

Qiao, S., Wang, H., Prentice, I. C. and Harrison, S. P. (2020) Extending a first-principles primary production model to predict wheat yields. Agricultural and Forest Meteorology, 287. 107932. ISSN 0168-1923 doi:

https://doi.org/10.1016/j.agrformet.2020.107932 Available at https://centaur.reading.ac.uk/89508/

It is advisable to refer to the publisher's version if you intend to cite from the work. See Guidance on citing.

To link to this article DOI: http://dx.doi.org/10.1016/j.agrformet.2020.107932

Publisher: Elsevier

All outputs in CentAUR are protected by Intellectual Property Rights law, including copyright law. Copyright and IPR is retained by the creators or other copyright holders. Terms and conditions for use of this material are defined in the End User Agreement.

\section{www.reading.ac.uk/centaur}

\section{CentAUR}

Central Archive at the University of Reading 
Reading's research outputs online 
${ }^{1}$ Ministry of Education Key Laboratory for Earth System Modeling, Department of Earth System

4 Science, Tsinghua University, Beijing 100084, China;

$5 \quad{ }^{2}$ Joint Center for Global Change Studies (JCGCS), Beijing 100875, China;

$6 \quad{ }^{3}$ AXA Chair of Biosphere and Climate Impacts, Department of Life Sciences, Imperial College London,

7 Silwood Park Campus, Buckhurst Road, Ascot, SL5 7PY, UK;

$8{ }^{4}$ Department of Biological Sciences, Macquarie University, North Ryde, NSW 2109, Australia;

$9{ }^{5}$ School of Archaeology, Geography and Environmental Sciences (SAGES), University of Reading,

10 Reading, RG6 6AH, UK.

11 *Corresponding author: Han Wang (wanghan_sci@yahoo.com)

12 Keywords

13 wheat; photosynthesis; crop yield; crop model; $\mathrm{CO}_{2}$ fertilization; harvest index

\section{Highlights}

15 1. A novel, simply formulated crop model with quantified uncertainties successfully predicts 16 wheat yields at research sites in China.

172 . The model captures the time course of GPP and variations in biomass and yield across sites 18 and between years.

$193 . \quad$ Sensitivity analyses and future projections indicate a positive response of wheat yield to rising

$20 \mathrm{CO}_{2}$, partially counteracted by a negative response to warming. 


\section{Data statement}

22

The climate and flux data from WeiShan can be obtained by contacting Huimin Lei (leihm@tsinghua.edu.cn). The flux data for YuCheng, the climate, LAI, crop data used the in this manuscript are publicly available from the National Ecosystem Research Network of China CNERN (http://www.cnern.org.cn/). All climate data driving the PC model runs for future and the model outputs of LPJmL, EPEIC, GEPIC are publicly available from Inter-Sectoral Impact Model Intercomparison Project-2b (ISIMIP2b: https://www.isimip.org/protocol/\#isimip2b/). The PC model code will be available from Mendeley data.

\section{Abstract}

Climate exerts a major influence on crop development and yield. Despite extensive modelling efforts, there is still considerable uncertainty about the consequences of a changing climate for the yields of major crops. Existing crop models are complex and rely on many assumptions and parameters, motivating a quest for more parsimonious models with stronger theoretical and empirical foundations.

This paper presents a prototype of such a model for wheat, informed by measurements of gross primary production (GPP), biomass and yield at research sites across the wheat-growing regions of China. First, GPP was predicted using a recently developed first-principles model driven only by climate, carbon dioxide $\left(\mathrm{CO}_{2}\right)$ concentration, and light absorbed by leaves. Modelled GPP was shown to agree well with eddy-covariance measurements. Second, the data were used to show that above-ground biomass (AB) is proportional to time-integrated GPP, and that grain yield shows a saturating relationship with AB. Simple empirical equations based on these findings were combined with modelled GPP to predict yield, including propagated errors due to parameter uncertainty in both the GPP model and the 
empirical equations. The resulting 'hybrid' model, applied in a variety of climates, successfully predicted measured interannual variations in $\mathrm{AB}$ and yield. Third, the model was extended to include a phenology scheme, a mass-balance equation relating mean leaf area index to accumulated GPP over growth phase, and an independently observed response of leaf mass-per-area to $\mathrm{CO}_{2}$. Sensitivity analyses and scenario runs with this extended model showed a positive but saturating (at $\sim 600 \mathrm{ppm}$ ) response of yield to rising $\mathrm{CO}_{2}$, consistent with experimental evidence. This positive effect was partially counteracted by a net negative response of yield to increasing temperature, caused by increasing photorespiration and an accelerated growth cycle.

\section{Introduction}

An adequate food supply is an essential basis for economic development and social stability in the context of increasing population and continuing anthropogenic climate change (Porter et al., 2014). As one of the world's four major crops (with maize, rice and soybean), wheat provides about a quarter of the world's cereal production (FAOSTAT, 2018) which, in turn, provides two-thirds of human caloric intake (Zhao et al., 2017). Wheat was introduced from the Near East and been cultivated in China since the late $6^{\text {th }}$ to early $5^{\text {th }}$ millennium BP (Betts et al., 2014). China is now both the largest producer and the largest consumer of wheat (Wang et al., 2009). Current wheat production in China exceeds $134 \mathrm{Mt}$ of grain per year. This is more than $17 \%$ of the total global wheat production, and about $22 \%$ of the total cereal production of China (FAOSTAT, 2018). Thus, even a small fluctuation in China's wheat production could potentially impact not only the Chinese economy but also global food security.

The growth and harvestable yield of wheat are determined by environmental factors (Asseng et al., 2004) but also strongly influenced by management (He et al., 2015). Light, $\mathrm{CO}_{2}$, temperature, water 
and nutrient availability define the basic conditions for the growth and development of the crop. Light and $\mathrm{CO}_{2}$ directly affect photosynthesis (Gerbaud and Andre, 1980); temperature further influences growth and development processes including germination, anthesis and harvest (Asseng et al., 2011; He et al., 2015; Liu et al., 2018; Porter and Gawith, 1999; Tao et al., 2012); water and nutrient availability principally influence foliage cover (Nielsen and Halvorson, 1991; Pan et al., 2019) and therefore the absorption of light for photosynthesis. However, the basic conditions of wheat growth, especially temperature and $\mathrm{CO}_{2}$ concentration, are changing. Temperatures in China have risen by $1.2^{\circ} \mathrm{C}$ over the past few decades (Cao et al., 2017; Piao et al., 2010) and continued warming is expected in the coming decades (Kirtman et al., 2014). Winter is warming faster than summer (Piao et al., 2010; Wu et al., 2017) and this situation is potentially unfavorable to the production of wheat (Brooking, 1996). On the other hand, atmospheric $\mathrm{CO}_{2}$ already exceeds $400 \mathrm{ppm}$, more than $40 \%$ above its preindustrial level and is expected to continue rising (Collins et al., 2014). For $\mathrm{C}_{3}$ crops (including wheat) the effect of rising $\mathrm{CO}_{2}$ level on photosynthesis is positive (Ainsworth and Rogers, 2007; Boylan, 2016; Sage et al., 1989), leading to higher photosynthetic productivity and potentially also grain yield (Lawlor and Mitchell, 1991). Improved management practices (e.g. fertilization, irrigation) and crop breeding have also contributed to increased wheat yield (Qin et al., 2015; Yu et al., 2019) under current climate conditions, and this trend is expected to continue.

The combined effects of changes in climate, $\mathrm{CO}_{2}$ and management are highly uncertain (Challinor and Wheeler, 2008) and numerical models are needed to project future trends in yield in different regions, and thereby to facilitate adaptation in the food production system. Such models should integrate knowledge from experiments and observations with theoretical understanding. Crop models have been under development for at least 40 years, and there are now many models with the technical 
capacity to simulate the growth and development of wheat (Blanc, 2017; Huang et al., 2016; Palosuo et al., 2011). However, current crop models require detailed input information that is challenging to collect over large scales and potentially subject to change in a dynamic environment. Moreover, intermodel comparisons have revealed large differences between model predictions of both current yields and future trends (Liu et al., 2019; Nelson et al., 2014; Ostberg et al., 2018). This situation parallels that for natural vegetation models (Prentice et al., 2015), and suggests that current crop models contain untested and potentially incorrect assumptions. Recently, however, progress has been made in developing simpler vegetation models, based on theoretical principles but drawing extensively on empirical data to test each model component (Franklin et al., 2017; Wang et al., 2017). Here we adopt this novel approach to develop a prototype model to predict wheat growth and yield.

The starting point for this model ('PC', for P crop: see Fig. 1) was the universal $\mathrm{C}_{3}$ primary production model 'P' (Stocker et al., 2019; Wang et al., 2017). The P model is a theoretically derived and extensively tested light use efficiency (LUE) model that predicts gross primary production (GPP) as a function of climate, absorbed light and $\mathrm{CO}_{2}$ on time steps of a week to a month. Further model development and testing of the PC model, presented here, used measurements of GPP, biomass and yield at research sites across the wheat-growing regions of China. In the first step of the analysis, the original P model was applied to predict GPP at two flux-tower sites situated in wheat crops in order to test its performance. In the second step, simple empirical equations were fitted to experimental data at several field research sites in order to relate accumulated GPP to aboveground biomass $(\mathrm{AB})$, and $\mathrm{AB}$ to grain yield. These equations were combined with the P model to predict yields for different sites and years; these predictions were compared to observed yields. Uncertainties in predicted yields due to key parameters of the P model, and to the fitted coefficients of the empirical equations, were quantified. In 
the third step, the model was extended to represent the responses of yield to environmental change by the inclusion of (a) a general scheme to predict phenology, (b) a mass-balance equation quantifying leaf area index (LAI) consistent with a given GPP, and (c) an observed relationship between leaf massper-area (LMA) and the $\mathrm{CO}_{2}$ concentration experienced during crop growth. These extensions allowed modelled light absorption to be influenced by changes in growing-season length, and changes in modelled GPP to feed back to LAI. The extended model was applied at six field sites to project future wheat yields under different combinations of increasing $\mathrm{CO}_{2}$ and temperature, in a sensitivity analysis for combinations of $\mathrm{CO}_{2}$ and temperature increase, and in alternative scenario runs for future $\mathrm{CO}_{2}$ and temperature change.

\section{Material and methods}

\subsection{The P model}

The $\mathrm{P}$ model is based on the standard biochemical model of $\mathrm{C}_{3}$ photosynthesis (Farquhar et al., 1980), with additional formulations that allow photosynthetic capacities and stomatal behaviour to acclimate to environmental conditions on weekly to monthly time scales (Wang et al., 2017). Instantaneous photosynthetic rates according to the standard model are the lesser of the electron transport-limited rate $\left(A_{\mathrm{J}}\right)$ and the carboxylation-limited rate $\left(A_{\mathrm{C}}\right) . A_{\mathrm{C}}$ is proportional to the Rubisco capacity $\left(V_{\mathrm{cmax}}\right)$. In the $\mathrm{P}$ model, $V_{\mathrm{cmax}}$ is assumed to acclimate to growth conditions such that the two rates are co-limiting under average daytime conditions (Maire et al., 2012; Smith et al., 2019). $A_{\mathrm{J}}$ is proportional to the absorbed photosynthetic photon flux density (PPFD) at low PPFD, increasing with PPFD towards a light-saturated rate that is proportional to the electron-transport capacity $\left(J_{\max }\right)$. In the

127 P model, acclimation of $J_{\max }$ parallels that of $V_{\text {cmax }}$ and their ratio is set to maximize the benefit $\left(A_{\mathrm{J}}\right)$ 
minus the cost of maintaining $J_{\max }$. Both $A_{\mathrm{C}}$ and $A_{\mathrm{J}}$ are functions of the leaf-internal $\mathrm{CO}_{2}$ partial pressure $\left(c_{\mathrm{i}}\right)$, whose ratio $(\chi)$ to the ambient $\mathrm{CO}_{2}$ partial pressure $\left(c_{\mathrm{a}}\right)$ is determined by stomatal responses to the relative rates of carbon gain and water loss. In the $\mathrm{P}$ model, $\chi$ is determined by the 131 least-cost criterion (Prentice et al., 2014), which minimizes the combined costs of maintaining the 132 Rubisco and water transport capacities. The three constraints (on $V_{\mathrm{cmax}}, J_{\max }$ and $\chi$ ) lead to an expression for weekly to monthly GPP under field conditions that has the mathematical form of a LUE model. That is, accumulated GPP is proportional to absorbed PPFD:

$\mathrm{GPP}=\Phi_{0} I_{\mathrm{abs}} m \sqrt{\left[1-\left(c^{*} / m\right)^{2 / 3}\right]}$

where

$m=\left(c_{\mathrm{i}}-\Gamma^{*}\right) /\left(c_{\mathrm{i}}+2 \Gamma^{*}\right)$

$c_{\mathrm{i}} / c_{\mathrm{a}}=\Gamma^{*} / c_{\mathrm{a}}+\left(1-\Gamma^{*} / c_{\mathrm{a}}\right) \xi /(\xi+\sqrt{\mathrm{D}})$

$\xi=\sqrt{ }\left[\beta\left(K+\Gamma^{*}\right) / 1.6 \eta^{*}\right]$

140 Here, $\Phi_{0}$ is the intrinsic quantum yield $\left(\mathrm{mol} \mathrm{CO}_{2} \mathrm{~mol}^{-1}\right) ; I_{\mathrm{abs}}$ is the PPFD intercepted and absorbed by 141 the canopy $\left(\mathrm{mol} \mathrm{m} \mathrm{m}^{-2} \mathrm{~s}^{-1}\right) ; c_{\mathrm{a}}$ is the ambient atmospheric $\mathrm{CO}_{2}$ partial pressure $(\mathrm{Pa}) ; \Gamma^{*}$ is the 142 photorespiratory compensation point $(\mathrm{Pa}) ; \eta^{*}$ is the viscosity of water, relative to its value at $25{ }^{\circ} \mathrm{C}$ 143 (dimensionless); $D$ is the vapour pressure deficit (Pa); $K$ is the effective Michaelis-Menten coefficient 144 of Rubisco $(\mathrm{Pa})$; and $c^{*}=0.41$ and $\beta=146$ are dimensionless constants, where $c^{*}$ has been estimated 145 from observed $J_{\max }: V_{\max }$ ratios and $\beta$ from observed stable carbon isotope ratios (Wang et al., 2017). The P model thus calculates GPP as the product of $I_{\mathrm{abs}}$, which is the product of incident PPFD and $147 f$ APAR (the fraction of incident PPFD absorbed by foliage) and LUE. LUE is the product of $\Phi_{0}, m$ and 
the square-root term in equation (1a). The parameters $\Gamma^{*}, \eta^{*}$ and $K$ depend on temperature (Bernacchi et al., 2001; Wang et al., 2017) and $\Gamma^{*}$ and $K$ depend on atmospheric pressure (Farquhar et al., 1980). The inputs to the model are air temperature $(T)$, relative humidity $(\mathrm{RH})$, incident PPFD, $f$ APAR, elevation (to calculate atmospheric pressure) and $c_{\mathrm{a}}$ (the product of the current year's mole fraction of $\mathrm{CO}_{2}$ with atmospheric pressure). When driven by satellite-derived fAPAR data, the model has been shown to reproduce monthly GPP well at eddy-covariance flux tower sites in natural vegetation worldwide (Stocker et al., 2019; Wang et al., 2017) and geographic patterns, seasonal cycles and interannual variability of GPP at flux tower sites located in different biomes, including croplands (Balzarolo et al., 2018).

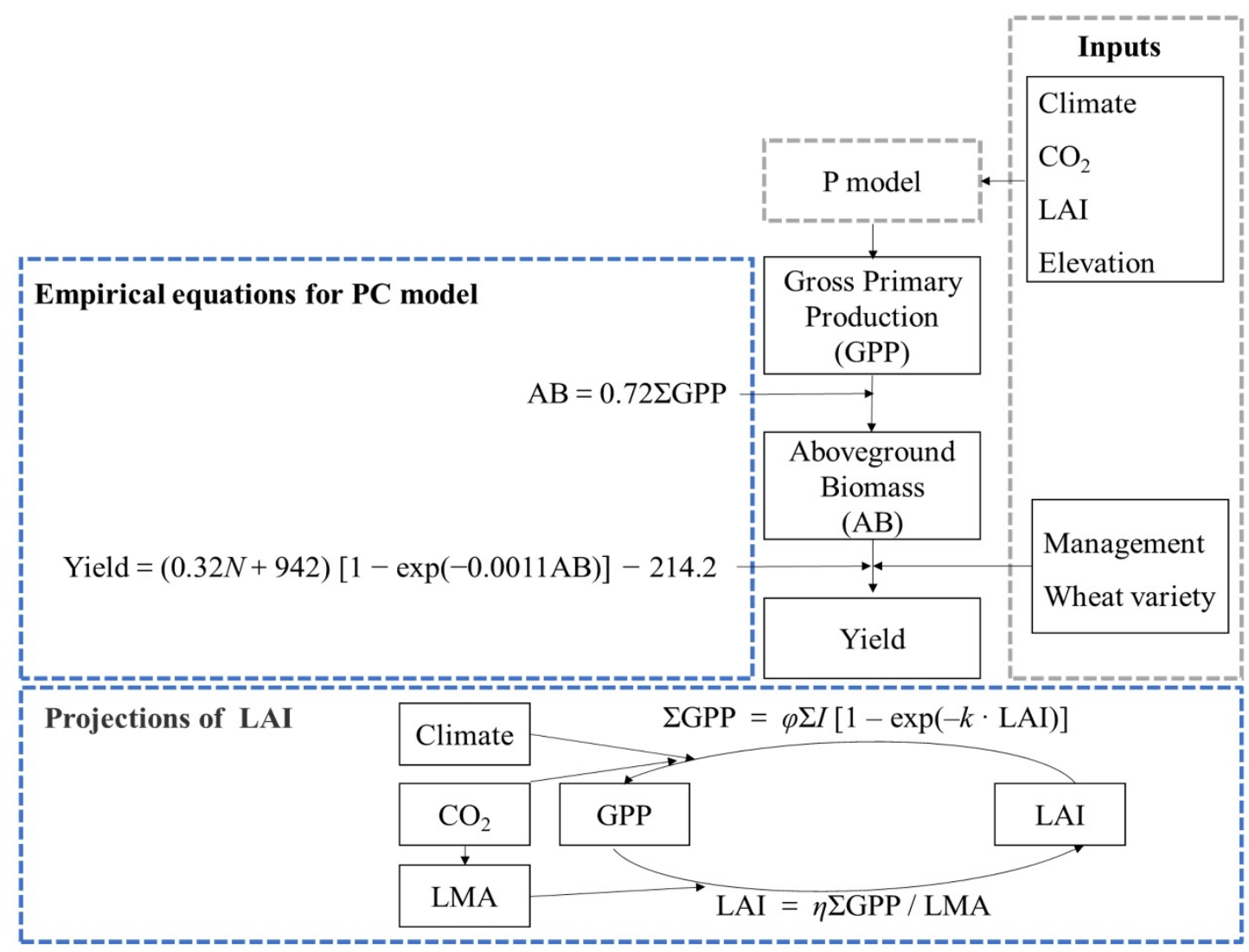

Figure 1: The structure of the PC model. $\Sigma$ GPP: accumulated gross primary production over growing season $\left(\mathrm{g} \mathrm{C} \mathrm{m}^{-2}\right) ; N$ : total application of nitrogen $\left(\mathrm{kg} \mathrm{N} \mathrm{hm}^{-2}\right)$. LAI: leaf area index (dimensionless). $\varphi$ : light use efficiency (\%). $\sum I$ : the sum of incident light over the growth phase (mol 
161 photo $\left.\mathrm{m}^{-2}\right) . k$ : a dimensionless constant, $(k=0.5) . \quad \eta$ : the fraction of $\Sigma$ GPP allocated to leaves 162 (dimensionless). LMA: leaf mass per area $\left(\mathrm{g} \mathrm{m}^{-2}\right)$. Climate here comprises temperature, relative 163 humidity and incident photosynthetic photon flux density. Boxes with grey dash line indicate the 164 already published model or known information, whereas the boxes with blue dash line indicate the 165 new model and its extension developed here.

We ran the P model on a weekly time step. The model has already been shown to work well on a 167 ten-daily time step (Balzarolo et al., 2018). We applied the 'BRC' model set-up (Stocker et al., 2019), 168 which differs from the original published version (Wang et al., 2017) by incorporating an observed 169 temperature-dependence of $\Phi_{0}$ (Bernacchi et al., 2003):

$170 \Phi_{0}=\left(0.352+0.021 T-0.00034 T^{2}\right) / 8$

\section{$171 \quad 2.2$ Sites and field data}

Data from 12 agricultural sites in the main wheat-growing area of China (see Fig. 2) were used

173 for the second step of model development and testing (see Table 1 and Table 2). More than $90 \%$ of 174 wheat production occurs in the areas where these sites are located (Wang et al., 2009), so they are 175 representative of the environmental conditions for wheat production in China. 


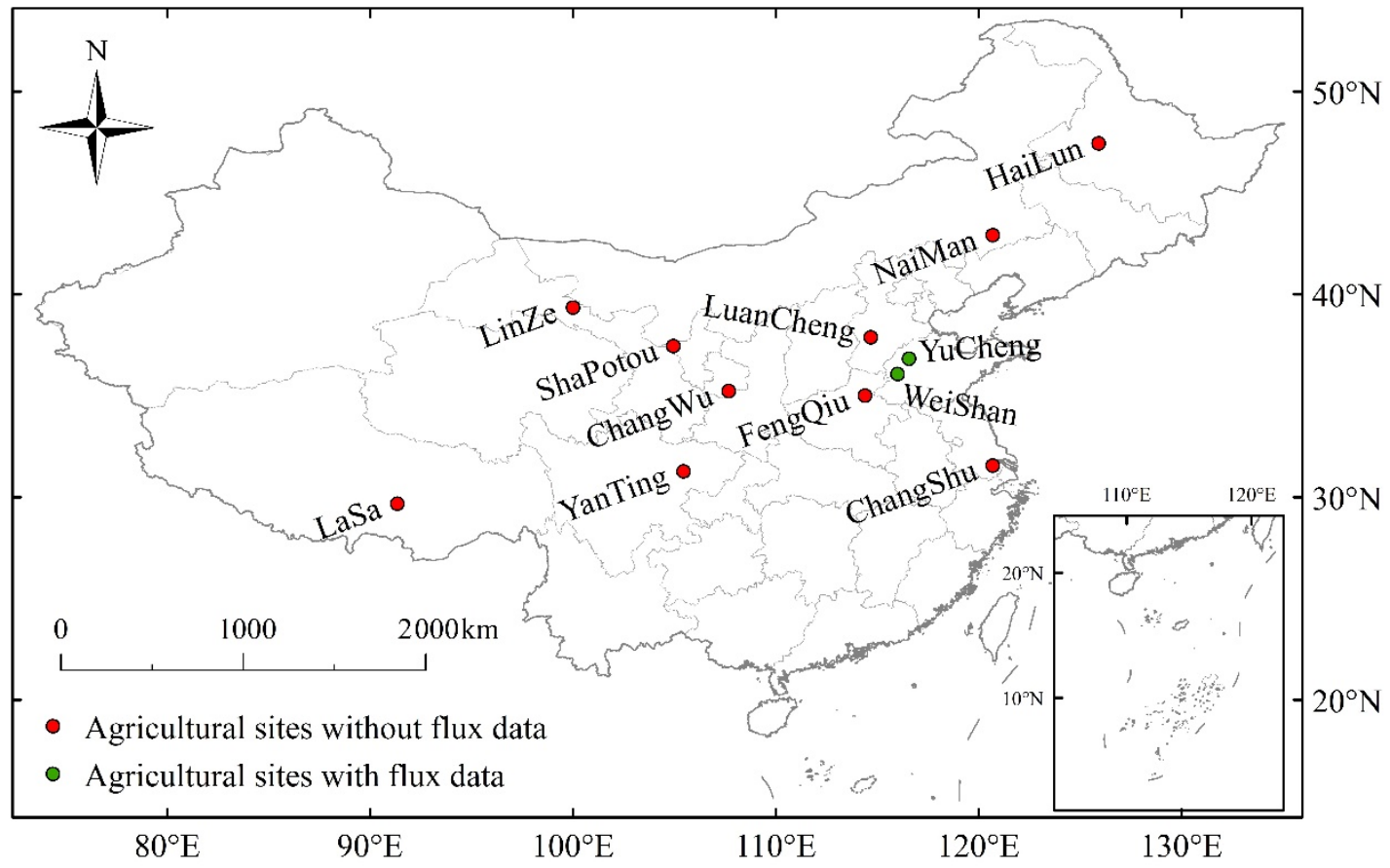

Figure 2: Locations of sites providing experimental data. 


\begin{tabular}{|c|c|c|c|c|c|c|}
\hline Site & Code & $\begin{array}{l}\text { Longitude } \\
\qquad\left(\mathrm{E},{ }^{\circ}\right)\end{array}$ & $\begin{array}{l}\text { Latitude } \\
\left(\mathrm{N},{ }^{\circ}\right)\end{array}$ & $\begin{array}{l}\text { Elevation } \\
\text { (m) }\end{array}$ & $\begin{array}{l}\text { Mean annual air } \\
\text { temperature } \\
\left({ }^{\circ} \mathrm{C}\right)\end{array}$ & $\begin{array}{c}\text { Mean annual } \\
\text { precipitation } \\
\text { (mm) }\end{array}$ \\
\hline WeiShan & WS & 116.83 & 36.23 & 20 & 13.3 & 532 \\
\hline YuCheng & $\mathrm{YC}$ & 116.57 & 36.82 & 22 & 13.2 & 530 \\
\hline ChangShu & $\mathrm{CS}$ & 120.7 & 31.55 & 3.1 & 16.6 & 1321.2 \\
\hline ChangWu & $\mathrm{CW}$ & 107.68 & 35.23 & 1220 & 9.1 & 580 \\
\hline LuanCheng & $\mathrm{LC}$ & 114.68 & 37.88 & 50.1 & 12.2 & 536.8 \\
\hline FengQiu & FQ & 114.4 & 35 & 67 & 13.9 & 605 \\
\hline YanTing & YG & 105.45 & 31.27 & 420 & 17.3 & 836 \\
\hline HaiLun & HL & 125.92 & 47.45 & 240 & 4 & 550 \\
\hline $\mathrm{LaSa}$ & LA & 91.33 & 29.67 & 3688 & 6 & 425 \\
\hline LinZe & $\mathrm{LZ}$ & 100 & 39.35 & 1384 & 1.5 & 550 \\
\hline NaiMan & $\mathrm{NM}$ & 120.7 & 42.92 & 358 & 5 & 425 \\
\hline ShaPotou & SP & 104.95 & 37.45 & 1250 & 9.6 & 1250 \\
\hline
\end{tabular}

178 Table 1: Background information about the sites. 


\begin{tabular}{|c|c|c|c|c|c|c|c|c|c|c|c|c|c|}
\hline Site code & Data span & $\begin{array}{c}\text { PPFD } \\
\left(\mathrm{mol} \mathrm{m}^{-2} \mathrm{day}^{-1}\right)\end{array}$ & $\begin{array}{c}\mathrm{T} \\
\left({ }^{\circ} \mathrm{C}\right)\end{array}$ & $\begin{array}{l}\mathrm{RH} \\
(\%)\end{array}$ & $\begin{array}{c}\mathrm{CO}_{2} \\
(\mathrm{ppm})\end{array}$ & LAI & $\begin{array}{c}\text { Elevation } \\
\text { (m) }\end{array}$ & $\begin{array}{c}\mathrm{AB} \\
\left(\mathrm{g} \mathrm{m}^{-2}\right)\end{array}$ & $\begin{array}{c}\text { Yield } \\
\left(\mathrm{g} \mathrm{m}^{-2}\right)\end{array}$ & $\begin{array}{c}\text { Fertilization } \\
\text { Irrigation }\end{array}$ & $\begin{array}{l}\text { Wheat } \\
\text { variety }\end{array}$ & $\begin{array}{c}\text { Flux data } \\
\left(\mathrm{g} \mathrm{C} \mathrm{m}^{-2} \text { day }^{-1}\right)\end{array}$ & Usage \\
\hline WS & 2006 & $\sqrt{ }$ & $\sqrt{ }$ & $\sqrt{ }$ & $\sqrt{ }$ & $\sqrt{ }$ & $\sqrt{ }$ & & & & & $\sqrt{ }$ & $\mathrm{a}$ \\
\hline $\mathrm{YC}$ & $2004-2015$ & $\sqrt{ }$ & $\sqrt{ }$ & $\sqrt{ }$ & $\sqrt{ }$ & $\sqrt{ }$ & $\sqrt{ }$ & $\sqrt{ }$ & $\sqrt{ }$ & $\sqrt{ }$ & $\sqrt{ }$ & $\sqrt{ }^{*}$ & $\mathrm{a}, \mathrm{b}, \mathrm{c}, \mathrm{d}$ \\
\hline $\mathrm{CS}$ & $2004-2015$ & $\sqrt{ }$ & $\sqrt{ }$ & $\sqrt{ }$ & $\sqrt{ }$ & $\sqrt{ }$ & $\sqrt{ }$ & $\sqrt{ }$ & $\sqrt{ }$ & $\sqrt{ }$ & $\sqrt{ }$ & & $\mathrm{c}, \mathrm{d}$ \\
\hline $\mathrm{CW}$ & $2004-2015$ & $\sqrt{ }$ & $\sqrt{ }$ & $\sqrt{ }$ & $\sqrt{ }$ & $\sqrt{ }$ & $\sqrt{ }$ & $\sqrt{ }$ & $\sqrt{ }$ & $\sqrt{ }$ & $\sqrt{ }$ & & $\mathrm{c}, \mathrm{d}$ \\
\hline FQ & $2004-2015$ & $\sqrt{ }$ & $\sqrt{ }$ & $\sqrt{ }$ & $\sqrt{ }$ & $\sqrt{ }$ & $\sqrt{ }$ & $\sqrt{ }$ & $\sqrt{ }$ & $\sqrt{ }$ & $\sqrt{ }$ & & $\mathrm{c}, \mathrm{d}$ \\
\hline $\mathrm{LC}$ & 2004-2015 & $\sqrt{ }$ & $\sqrt{ }$ & $\sqrt{ }$ & $\sqrt{ }$ & $\sqrt{ }$ & $\sqrt{ }$ & $\sqrt{ }$ & $\sqrt{ }$ & $\sqrt{ }$ & $\sqrt{ }$ & & $\mathrm{c}, \mathrm{d}$ \\
\hline YG & 2004-2015 & $\sqrt{ }$ & $\sqrt{ }$ & $\sqrt{ }$ & $\sqrt{ }$ & $\sqrt{ }$ & $\sqrt{ }$ & $\sqrt{ }$ & $\sqrt{ }$ & $\sqrt{ }$ & $\sqrt{ }$ & & $\mathrm{c}, \mathrm{d}$ \\
\hline $\mathrm{HL}$ & $2005-2006$ & & $\sqrt{ }$ & & & & $\sqrt{ }$ & $\sqrt{ }$ & $\sqrt{ }$ & $\sqrt{ }$ & $\sqrt{ }$ & & $\mathrm{c}$ \\
\hline LS & 2004-2015 & & $\sqrt{ }$ & & & & $\sqrt{ }$ & $\sqrt{ }$ & $\sqrt{ }$ & $\sqrt{ }$ & $\sqrt{ }$ & & $\mathrm{c}$ \\
\hline $\mathrm{LZ}$ & 2006 & & $\sqrt{ }$ & & & & $\sqrt{ }$ & $\sqrt{ }$ & $\sqrt{ }$ & $\sqrt{ }$ & $\sqrt{ }$ & & $\mathrm{c}$ \\
\hline NM & 2006 & & $\sqrt{ }$ & & & & $\sqrt{ }$ & $\sqrt{ }$ & $\sqrt{ }$ & $\sqrt{ }$ & $\sqrt{ }$ & & $\mathrm{c}$ \\
\hline SP & 2006 & & $\sqrt{ }$ & & & & $\sqrt{ }$ & $\sqrt{ }$ & $\sqrt{ }$ & $\sqrt{ }$ & $\sqrt{ }$ & & $\mathrm{c}$ \\
\hline
\end{tabular}

179 Table 2: Data details and use. $\checkmark$ : data are available; a: sites were used to test the P model; b: sites were used to derive the GPP to AB

180 relationship; c: sites were used to derive the AB to yield relationship; d: sites were used to test the final model. ${ }^{*}$ Two years (2004-2005) during

181 the data span are available for the flux data at YuCheng. 
Two flux tower sites (WeiShan, YuCheng; see Table 2 and Fig. 2) were used to test the GPP predictions. One full year of observations from WeiShan (2006) and two years of observations from YuCheng $(2004,2005)$ were available. The climate data (PPFD, $T$ and RH) and canopy coverage (here estimated from LAI by Beer's law), required as input to the P model, were obtained from on-site measurements for WeiShan provided by the original authors (Lei and Yang, 2010) and downloaded from the National Ecosystem Research Network of China (CNERN: http://www.cnern.org.cn/) for YuCheng. $\mathrm{CO}_{2}$ concentrations used are the annual global average obtained from the United States National Oceanic $\&$ Atmospheric Administration

(NOAA: https://www.esrl.noaa.gov/gmd/ccgg/trends/).

There are no data on $\mathrm{AB}$ or grain yield from WeiShan, although this information is available for YuCheng. We therefore used the two years of data from YuCheng to derive the relationship between GPP and AB. We obtained experimental data from ten additional agricultural sites providing information on $\mathrm{AB}$ and grain yield from CNERN. CNERN also provided data on climate (including PPFD, $T$ and RH), LAI, dates of the growing period, wheat varieties planted and management practices (including irrigation and the supply of total nitrogen, phosphate and potassium) for all of these sites. However, the records cover different periods (see Table 2): some sites only have data for one year (LZ, SP, NM); one site has data for two years (HL); the remaining sites have records spanning multiple years (CS, CW, FQ, LC, YG, LS). We used all the available data from these ten sites and YuCheng together (584 data points) to estimate the allocation relationship between AB and grain yield. We used data from six sites (CS, CW, FQ, LC, YG, YC) with records for more than two years to test the final model. We could not use the Lasa site for testing because there are no LAI data from this site.

Climate data were pre-processed on a weekly time step, with PPFD summed and $T$ and RH averaged. Then vapour pressure deficit $(D, \mathrm{kpa})$ was calculated according to the following equation (Campbell and Norman, 2012):

$D=610.8 \exp [17.27 T /(T+237.3)](100-\mathrm{RH}) / 100$ 

from LAI:

where $k$ is a dimensionless constant, assigned a generic value of 0.5 . LAI was measured several times over the growing season, but the times of measurement varied from year to year and site to site. The LAI data used as input to test the P model (WS 2006, YC 2004-2005) are based on eight to ten observations at each site over growing season. We interpolated the data to weekly mean values using a polynomial regression of LAI against time. Measurements of LAI at the sites used to test the crop model (PC model) were made more sporadically (less than five observations per growing season) and therefore inadequate for polynomial regression. We derived LAI values for PC model test from the

217 MODIS LAI product (MCD15A3H: 4-day time-step and 500m resolution, 218 https://modis.gsfc.nasa.gov/). Since MODIS severely underestimates the observed LAI at the six test 219 sites, we calculated the relationship between observed and MODIS LAI by linear regression and used the slope of this regression to rescale the MODIS LAI data and derive weekly mean LAI.

\subsection{Derivation of allocation relationships}

We hypothesized that a fixed proportion $(\varepsilon)$ of accumulated GPP during the growing season would be allocated to above-ground biomass (AB). We calculated GPP accumulation ( $\Sigma$ GPP) from the

224 beginning of the growing season to the day when $\mathrm{AB}$ was measured, then derived an empirical relationship between $\mathrm{AB}$ and $\Sigma \mathrm{GPP}$ by linear regression. We used the slope of this linear regression as an estimate of $\varepsilon$.

We hypothesized that grain yield should increase, monotonically but not necessarily linearly, with $\mathrm{AB}$, and that this relationship might be influenced by wheat varieties and management practices. Nonlinear regression was used to derive an empirical relationship between grain yield and $\mathrm{AB}$, taking 

account of the effect of nitrogen supply and wheat variety on the relationship, meanwhile testing the

231 effects of irrigation and the application of phosphate and potash. Non-linear regression was performed 232 using a mixed-effects model in the nlm package of $\mathrm{R}$. The form of the fitted equation is as follows:

233 Yield $=(a \cdot N+b)[1-\exp (c \cdot \mathrm{AB})]+\mathrm{d}$

234 where $N$ is the total application of nitrogen $\left(\mathrm{kg} \mathrm{N} \mathrm{hm}^{-2}\right)$, and $a, b, c$ and $d$ are parameters to be fitted. 235 Wheat variety was considered as a random effect added to parameter $b$, thus allowing maximum yields 236 to differ by variety. The potential effects of other factors (irrigation, precipitation, mean temperature 237 during the growth season) were tested by examining the residuals from this regression. To check the 238 goodness of fit of the non-linear regression, linear regression was also performed both using all the 239 data together, and for each variety separately. The root mean squared error (RMSE) and Akaike 240 Information Criterion (AIC) were calculated as an indicator of the goodness of fit of each model.

\subsection{Model evaluation}

We tested the performance of the PC model by comparing interannual variations in predicted and observed $\mathrm{AB}$ and grain yield over multiple years at the six test sites (CS, CW, FQ, LC, YC, YG), using meteorological observations from each site to drive the model. The simulated accumulated GPP during the growing season was allocated to $\mathrm{AB}$ using the fixed ratio $(\varepsilon)$ obtained by linear regression, and $\mathrm{AB}$ at harvest was allocated to grain yield using the non-linear relationship described above (Equation 5).

247 The growing season was defined as the period when mean daily temperature was above $0^{\circ} \mathrm{C}$. 248 Interannual variation in yield provides an independent test of the model as no information on interannual variability was used in the derivation of empirical relationships used in the model.

There are two sources of uncertainty in the model predictions: the input data (climate and LAI) and the model parameters. We assumed the input data were reliable and focused on parameter uncertainty. We considered each of the sources of uncertainty in the individual equations in the P model 
253 independently, and combined these uncertainties using the standard error propagation formula 254 (Prentice and Thomas, 2018):

$255 \quad u^{2}(y)=\sum_{i}\left(\partial f / \partial x_{i}\right)^{2} u^{2}\left(x_{i}\right)$

256 where $u(y)$ is the standard uncertainty (of GPP or AB or yield), $\partial f / \partial x_{i}$ is the sensitivity to variable $x_{i}$ 257 (obtained by differentiating the individual equations), and $u\left(x_{i}\right)$ is the standard uncertainty of $x_{i}$.

\subsection{Model extension}

\subsubsection{Phenology scheme}

The phenology scheme for wheat was adopted from the LPJmL4 model (Bondeau et al., 2007; Schaphoff et al., 2018). Sowing and maturity dates were obtained from the datasets provided in the global gridded crop model inter-comparison project (Elliott et al., 2015). A phenological scalar $\left(f_{\mathrm{PHU}}\right)$ ranging from 0 at sowing to 1 at harvest was computed:

265 where $n$ is the number of days from sowing, $T_{m}$ is the daily mean air temperature $\left({ }^{\circ} \mathrm{C}\right)$ and $T_{b}$ is the 266 base temperature (here $0^{\circ} \mathrm{C}$ ) and used to determine LAI development, using a sigmoid curve during 267 the growth phase and a quadratic curve during the senescent phase. (In the absence of water and 268 nutrient stresses, LAI is assumed to follow this optimal curve. During the growth phase:

$269 f_{\mathrm{LAImax}}=f_{\mathrm{PHU}} /\left[f_{\mathrm{PHU}}+\exp \left(l_{1}-l_{2} \cdot f_{\mathrm{PHU}}\right)\right]$

270 where LAI is a time-dependent fraction $\left(f_{\mathrm{LAImax}}\right)$ of maximum LAI $\left(\mathrm{LAI}_{\max }\right)$, and $l_{1}$ and $l_{2}$ are the first 271 and second inflection points. During the senescence phase:

$272 f_{\text {LAImax }}=\left[\left(1-f_{\text {PHU }}\right)^{2} /\left(1-f_{\text {PHUsen }}\right)^{2}\right]\left(1-f_{\text {LAImax-harvest }}\right)+f_{\text {LAImax-harvest }}$ 
273 where $f_{P H U s e n}$ is the fraction of PHU when senescence begins, and $f_{\text {LAImax-harvest }}$ is the fraction of 274 maximum LAI at harvest (here fixed to zero). The $f_{\mathrm{PHU}}$ values corresponding to the $l_{1}$ and $l_{2}$ inflection 275 points were derived from Figure 4 in Bondeau et al. (2007) and the parameter values of $l_{1}$ and $l_{2}$ were 276 calculated for these $f_{\mathrm{PHU}}$ values using the method of Neitsch et al. (2011). We used values for the $l_{1}$ 277 and $l_{2}$ inflection points of 0.89 and 10 , respectively.

Prognostic calculation of LAI was enabled by fitting a linear relationship between leaf biomass and $\mathrm{AB}$ based on data from the field sites, then solving for LAI in the mass-balance equation:

282 where $\eta$ is the fraction of $\Sigma$ GPP allocated to leaves, LMA is the leaf mass-per-area $\left(\mathrm{g} \mathrm{m}^{-2}\right), \varphi$ is the modelled LUE (the ratio of modelled GPP, following equation (1), to absorbed PPFD), and $\Sigma I$ is the accumulated incident PPFD (mol photon $\left.\mathrm{m}^{-2}\right) . k$ is a dimensionless constant $(k=0.5)$. Equation (10) indicates that the LAI demand (left hand side) must equal to its supply (right hand side). The LAI demand represents the allocation of accumulated GPP to canopy to support a certain level of LAI. The LAI supply represents the carbon accumulation supported by a certain level of LAI. $\eta$ was estimated from the observed data on leaf biomass and $\Sigma$ GPP from the YuCheng site in 2004 and 2005, LMA was set at $35.7 \mathrm{~g} \mathrm{~m}^{-2}$ corresponding to the mean observed value at YuCheng and allowed to increase linearly with $\mathrm{CO}_{2}$ using the observed slope $\left(0.05 \mathrm{~g} \mathrm{~m}^{-2}\right.$ per $\left.\mathrm{ppm}\right)$ from Thilakarathne et al. (2013).

\subsection{Model application}

\subsubsection{Sensitivity analysis}

Using 2005 as a baseline (baseline temperature is the weekly mean temperature over the growing season and baseline $\mathrm{CO}_{2}$ is $380 \mathrm{ppm}$ ), we ran simulations with the extended model, including 
prognostic phenology and dynamic LAI and LMA, with temperature increasing by $0.05^{\circ}$ increments up to $5^{\circ}$ above the baseline temperature and $\mathrm{CO}_{2}$ concentration increasing by increments of 5 ppm up to $500 \mathrm{ppm}$ above the baseline $\mathrm{CO}_{2}$ concentration. These changes were superimposed on the weekly mean temperatures and on the annual $\mathrm{CO}_{2}$ concentration. All other inputs (radiation, relative humidity, management practices and wheat variety) were fixed at their 2005 values.

\subsubsection{Future scenarios}

We used the model to examine the consequences of potential future climate changes on wheat (ISIMIP2b: https://www.isimip.org/protocol/\#isimip2b/). Climate data, including daily mean temperature, photosynthetically active radiation (assumed to be half of downward shortwave radiation) and relative humidity from the MIROC5 simulations, and $\mathrm{CO}_{2}$ concentrations, for two scenarios (RCP2.6 and RCP6.0) were used to run the PC model at six test sites (CS, CW, FQ, LC, YC, YG) from 2006 to 2099. Management practices and wheat varieties were unchanged from 2005.

The LPJmL (Bondeau et al., 2007; Muller and Robertson, 2014; Schaphoff et al., 2018), GEPIC (Liu et al., 2007) and PEPIC (Liu et al., 2016) crop models have been used to simulate future wheat yields in ISIMIP2b. We compared our future projections of yield with results from these three models. In ISIMIP2b, these models ran simulations with full irrigation and no irrigation. In order to eliminate 312 the effect of variable water supply, we compared our results with those from the full-irrigation run. We extracted simulated wheat yields at our six test sites from the results of each model for the RCP2.6 and RCP6.0 scenarios. Further information about these three models, including input data, leaf area, 315 phenological development, yield formulation and stresses considered, is given in Table S1. 


\subsection{Modelled versus observed GPP}

Predicted weekly GPP values were consistent with the observations from the flux towers, both in 319 their magnitudes (Fig. 3a) and their patterns over the growing season (Fig. 3b). Observed and predicted 320 GPP were highly correlated $\left(R^{2}=0.81, \mathrm{RMSE}=10.1 \mathrm{~g} \mathrm{C} \mathrm{m}^{-2}\right.$ week $\left.^{-1}\right)$ and the slope of the relationship was close to $1: 1$ (slope $=1.07 \pm 0.08)$ with a non-significant offset (intercept $=0.79 \pm 4.67 \mathrm{~g} \mathrm{C} \mathrm{m}^{-2}$ week $\left.^{-1}\right)$.
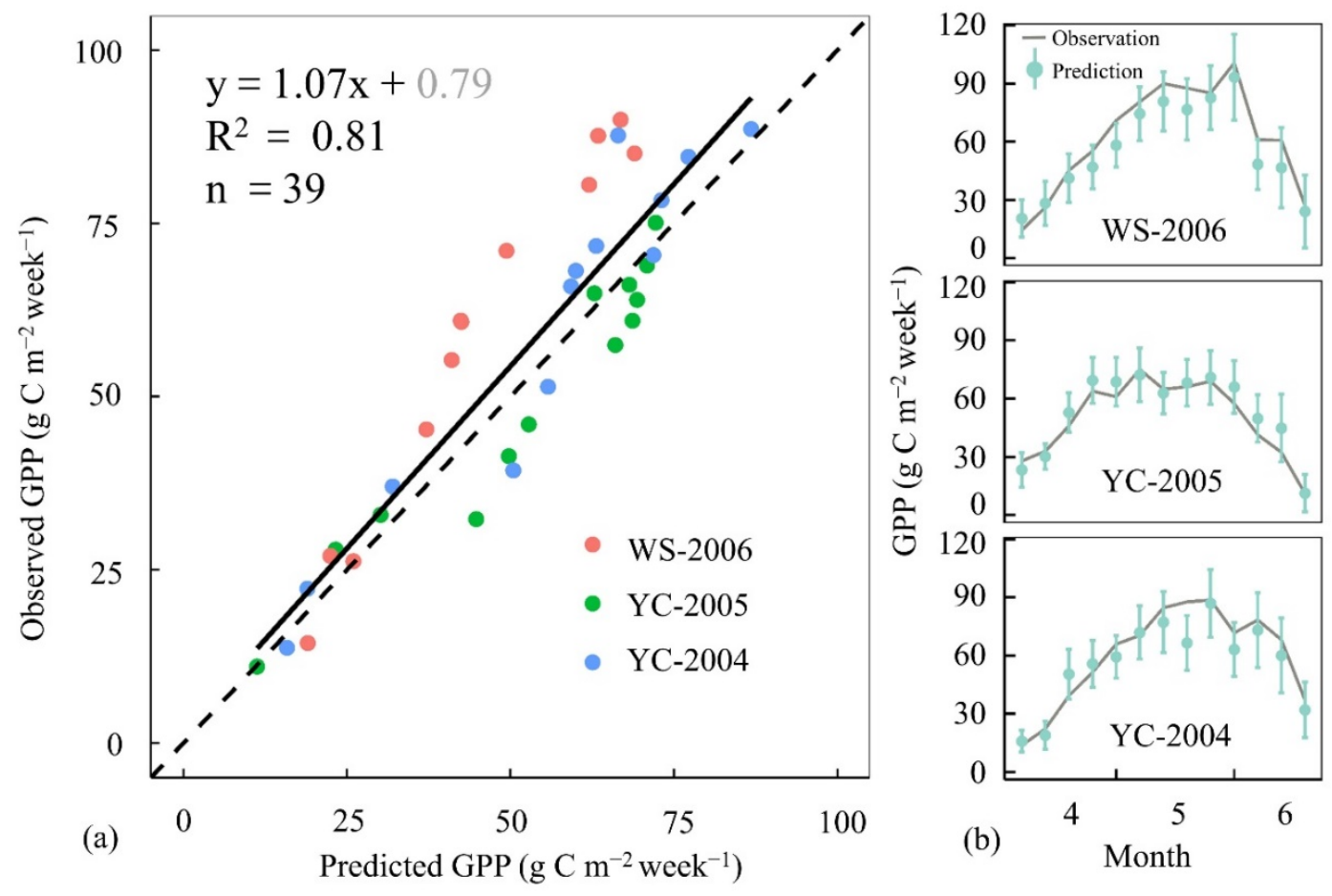

Figure 3: Comparison of predicted and observed gross primary production at two sites. (a)

Scatterplot. The thick black line is the linear regression. The grey number is not significant; (b) GPP during the growing season (weekly sums). WS-2006, YC-2005 and YC-2004, represents WeiShan in 2006, YuCheng in 2005 and YuCheng in 2004, respectively. 
A strong linear relationship (Fig. 4) was shown between AB and accumulated GPP ( $r=0.92)$ with an estimated $72 \%$ (slope, $\varepsilon=0.72$ ) of accumulated GPP allocated to AB. The intercept was statistically significant, but small enough to be neglected.

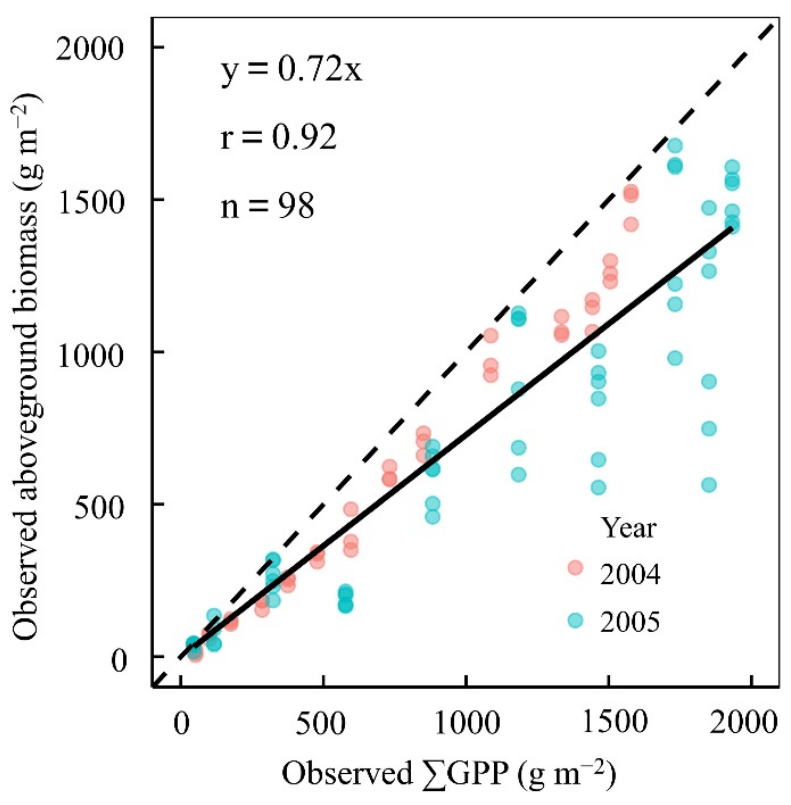

Figure 4: The proportion of accumulated gross primary production (GPP) allocated to

aboveground biomass. The data are observations during the wheat growth season at YuCheng from 2004 to 2005 . All values were accumulated from green-up to measurement time.

\subsection{The relationship between yield and $A B$}

Yield was shown to be a saturating function of AB (Fig. 5a). Nitrogen addition affected the overall level of allocation (Fig. 5b), with higher nitrogen supply causing high allocation to $\mathrm{AB}$. The relationship was affected by wheat variety, and a saturating relationship can also be shown within each of the varieties that covers a large range of $\mathrm{AB}$ (range $>1800 \mathrm{~g} \mathrm{~m}^{-2}$ ), with a substantially smaller RMSE and AIC compared to linear fits (Fig. S1). Moreover, the slopes of linear regressions fitted to each variety separately decline with the mean value of $\mathrm{AB}$ for the variety (Fig. 7 and Fig. S2). In other words, at the high end of $\mathrm{AB}$ values, the increment in yield diminishes with the increment in $\mathrm{AB}$. These 
results indicate that the non-linear, saturating relationship of yield to $\mathrm{AB}$ applies generally, both within and across varieties.
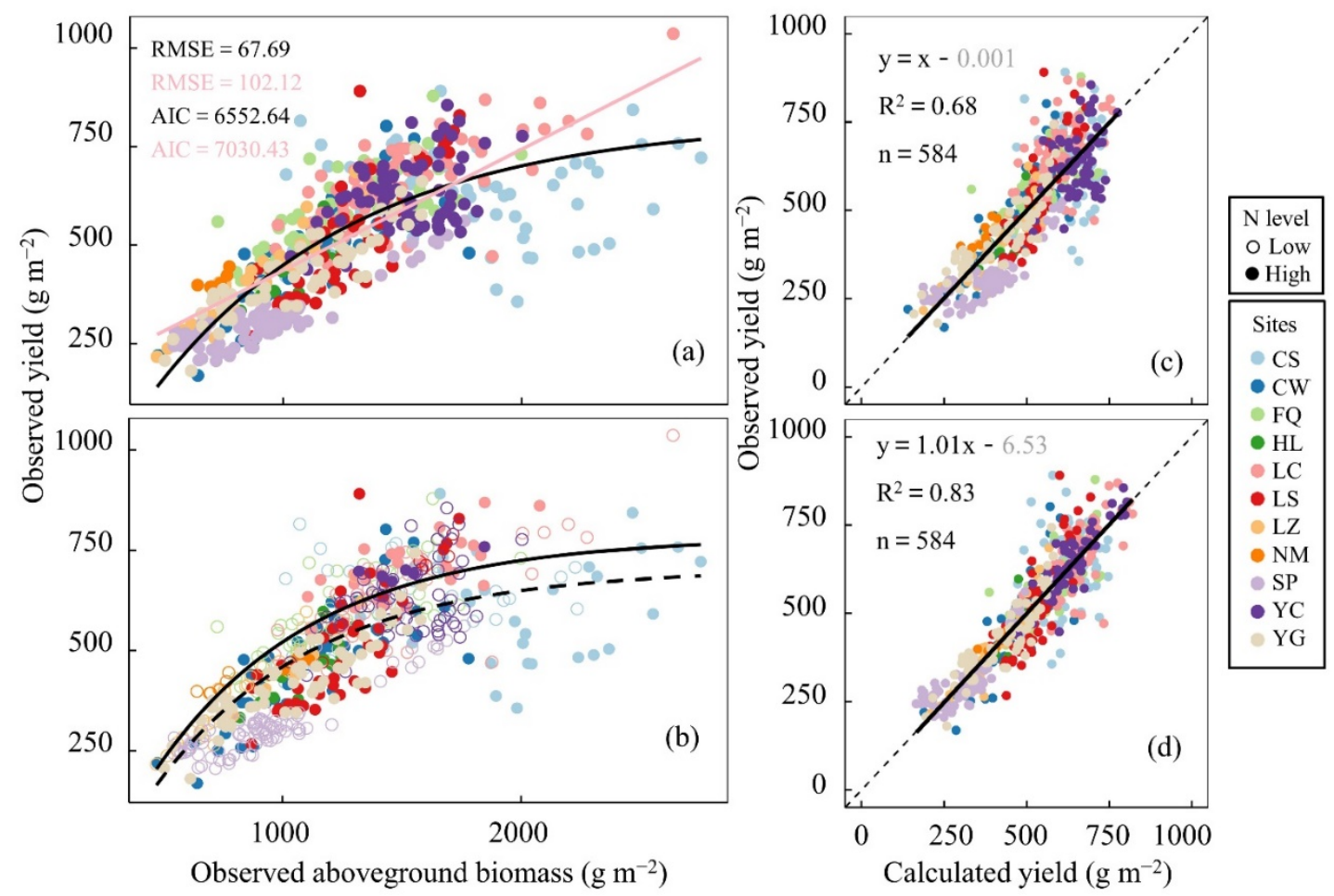

Figure 5: Results of the mixed-effects model. (a) Yield versus aboveground biomass (AB). Pink

349 line is linear regression and black line is non-linear regression. (b) Yield trend with $A B$, including the 350 effect of nitrogen addition. The solid line is the fitted curve of yield with $A B$ at high nitrogen level 351 (pure nitrogen added $=300 \mathrm{~kg} \mathrm{hm}^{-2}$ ) and the dotted line is at low nitrogen level (pure nitrogen added $352=100 \mathrm{~kg} \mathrm{hm}^{-2}$ ). The open and closed circles represent the observations with total application of pure nitrogen at levels above and below $200 \mathrm{~kg} \mathrm{hm}^{-2}$, respectively. (c) Scatterplot including AB and nitrogen 354 as predictors. (d) Scatterplot including AB, nitrogen and variety as predictors. Grey numbers are non355 significant. 

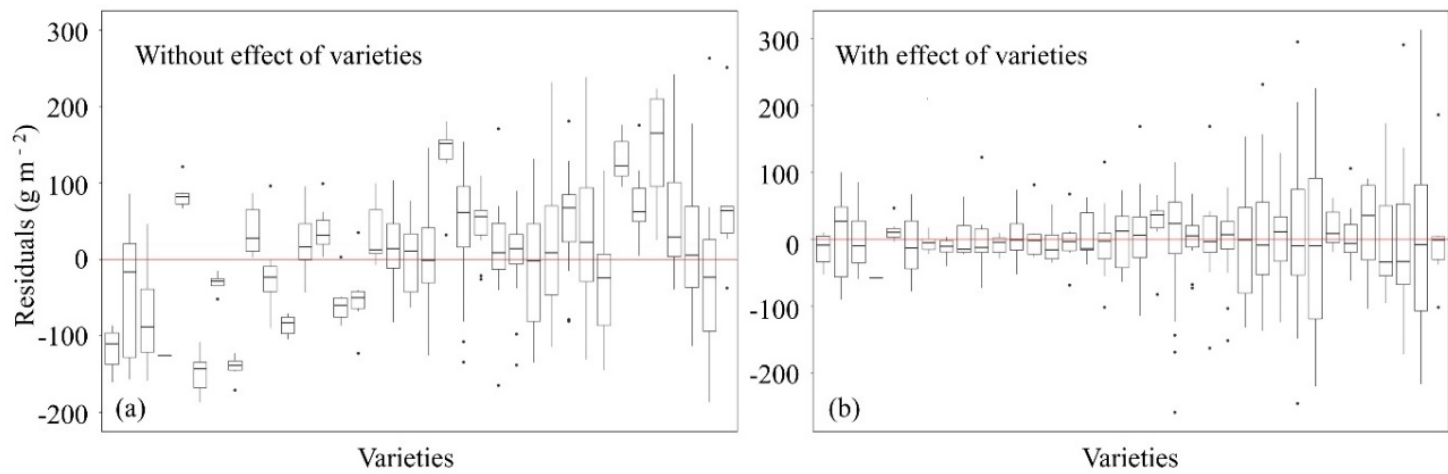

Figure 6: The relationship between residuals and wheat varieties. (a) Without the random effect of variety; (b) with this effect. Each box represents a wheat variety. The red line is zero and the black dots are outliers.

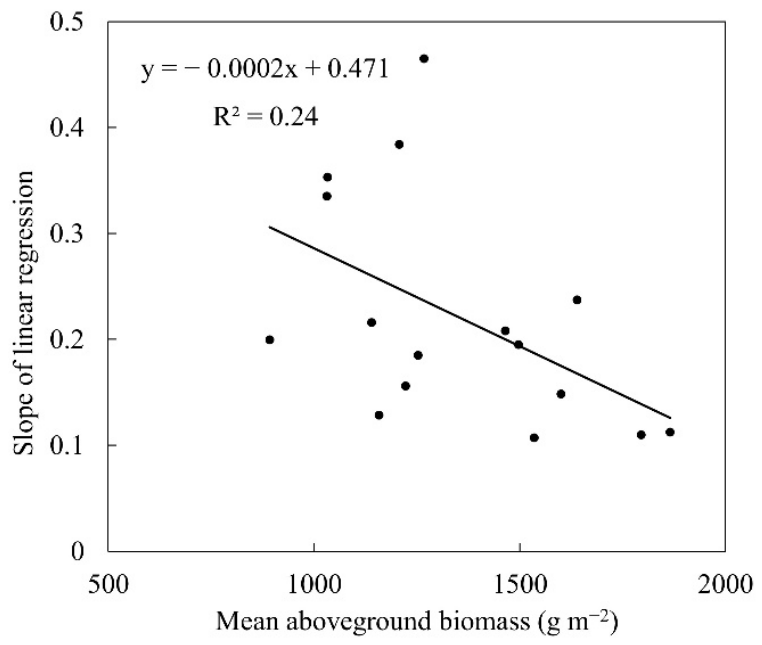

Figure 7: The fitted slope and mean value of aboveground biomass based on the linear

The comparison between simulated and observed yields improved when variety was taken into account (Fig. 5c compared to Fig. 5d). Residuals of the non-linear regression were reduced (Fig. 6), and the correlation between predicted and observed yield improved ( $R^{2}$ increased from 0.68 to 0.83 ).

367 Irrigation, mean temperature over the growing season, and the supply of phosphate and potassium had 
no significant effects on the relationship between $\mathrm{AB}$ and yield $(\mathrm{P}>0.05)$ on yield (Fig. S3), indicating that the first-order effects of these factors are already subsumed in AB.

\subsection{Model evaluation}

The model captured the pattern of interannual variation in $\mathrm{AB}$ (see Fig. 8) and, although there were some anomalous years, the predicted $\mathrm{AB}$ was generally within the range of the observations. The correlation between predicted and observed AB was moderate $(r=0.40)$. The simulated and observed yields matched reasonably well $(r=0.61)$ and interannual variations in grain yield were captured (Fig. 9 and Table S2), with observations almost always within the uncertainty range of the predictions.
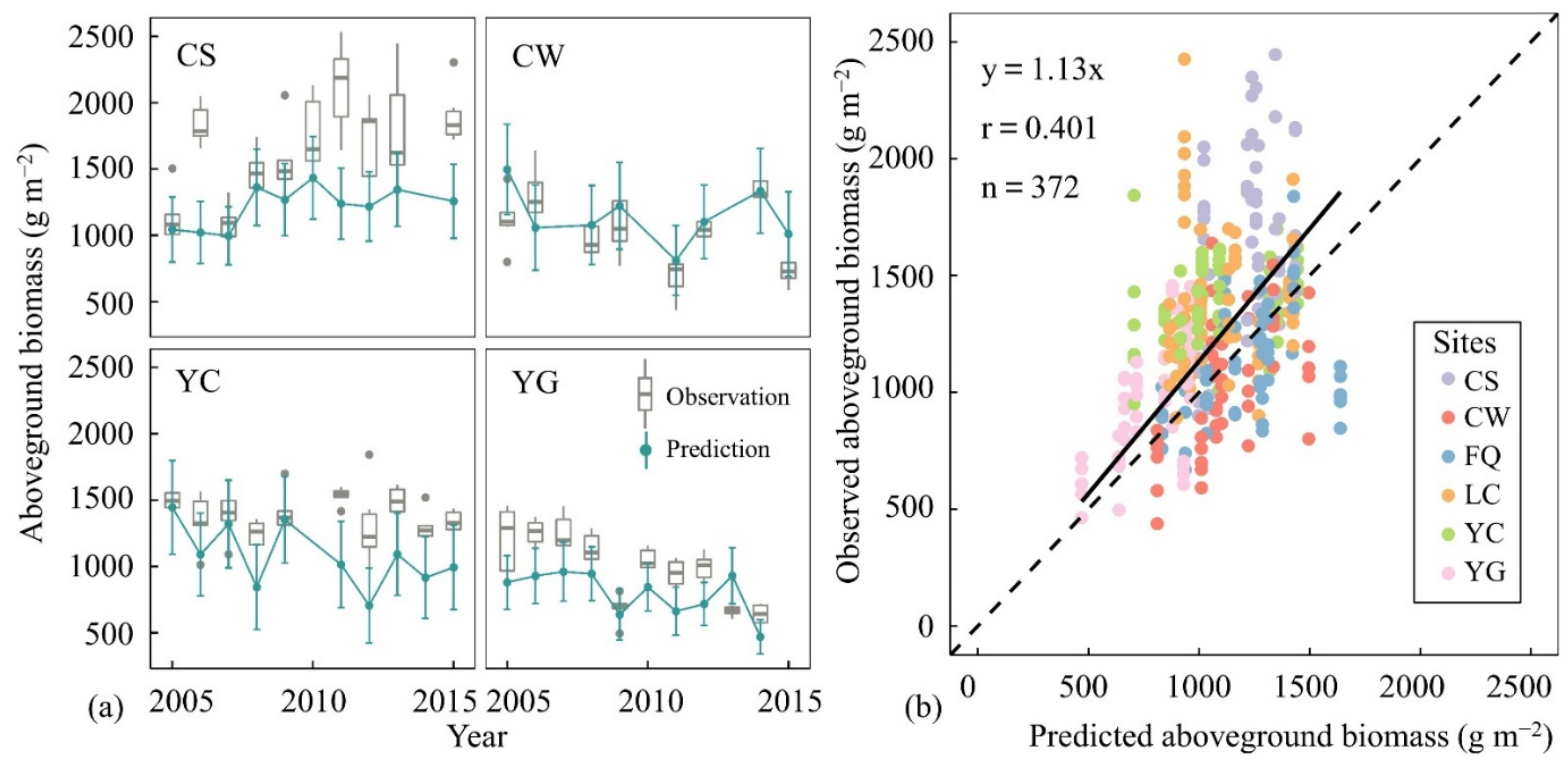

Figure 8: Comparisons of observed and modelled aboveground biomass. (a) Interannual observed $\mathrm{AB}$ at all sites. 

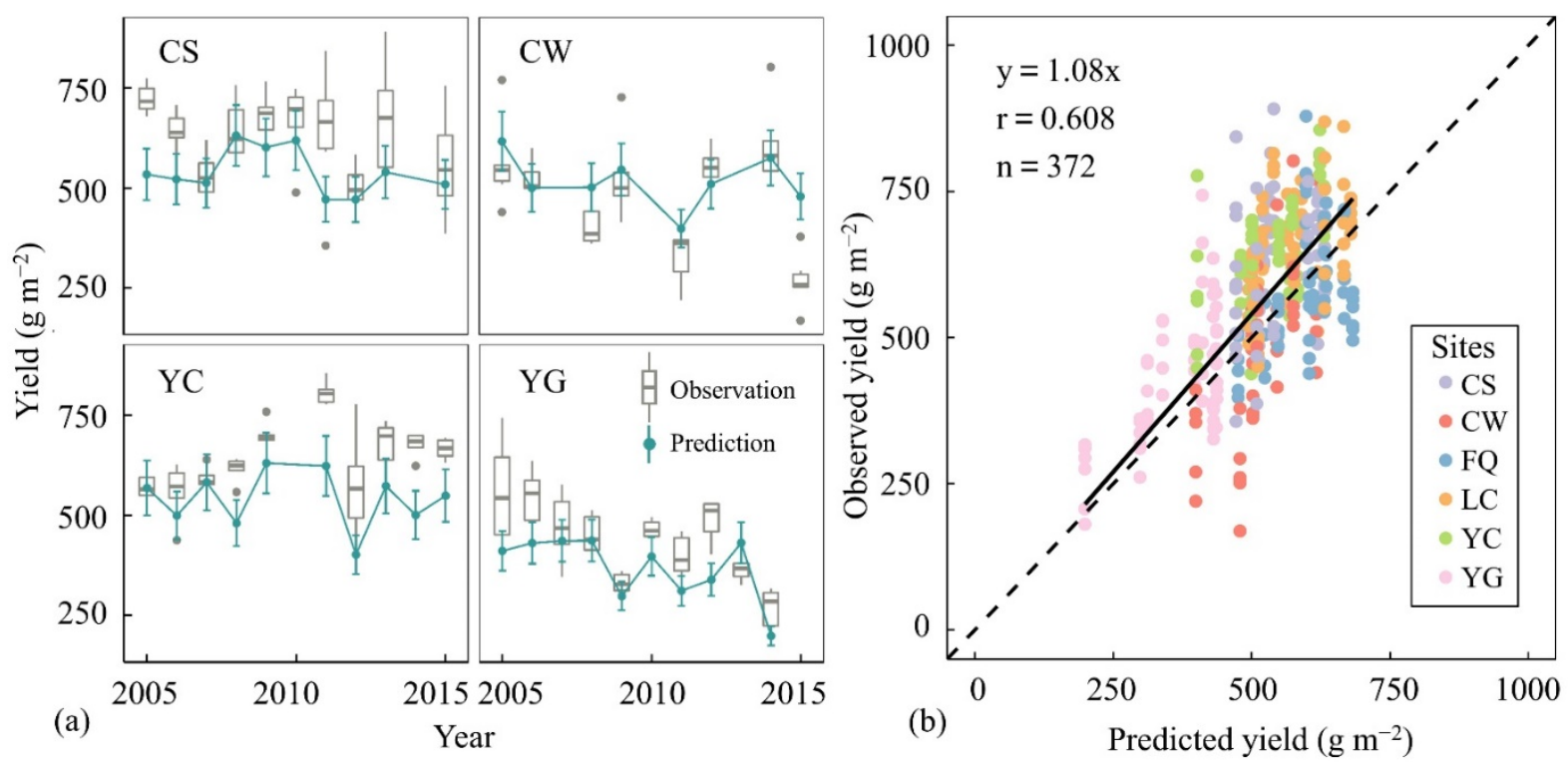

Figure 9: Comparisons of observed and modelled yield. (a) Interannual variations at four sites:

ChangShu, ChangWu, YuCheng, YangTing. (b) Scatterplot of predicted and observed yield at all sites.

\subsubsection{Uncertainty analysis}

Uncertainty in model predictions could originate either in the input data (climate, LAI) or in the model. We assumed that the input data were reliable, and used YuCheng 2005 as a case study to analyse the uncertainties due to the following model parameters:

- The two most uncertain quantities $\left(\beta, c^{*}\right)$ in the $\mathrm{P}$ model (Prentice and Thomas, 2018). $\beta$ is the ratio of the unit costs for the maintenance of carboxylation and transpiration capacities, evaluated at $25^{\circ} \mathrm{C}$. It determines the value of the ratio of leaf-internal to ambient $\mathrm{CO}_{2}$ (an index of stomatal behaviour) under standard conditions. $c^{*}$ is the unit cost of maintaining electrontransport capacity and determines the extent to which optimum carboxylation capacity is lowered because of the cost of maintaining an equivalent capacity for electron transport (Equation 1).

- The proportionality constant $(\varepsilon)$ between biomass and accumulated GPP.

- The four main parameters $(a, b, c, d)$ from the formula relating yield to $\mathrm{AB}$ (Equation 5). 
The calculated uncertainties with respect to different model parameters for predicted GPP and yield are shown in Fig. 10. When the parameters were varied by $\pm 10 \%$, the total uncertainty of predicted GPP was $\sim 9 \%$. The largest source of this uncertainty $(\sim 6 \%)$ was associated with the parameter $c^{*}$, which is an important control on the magnitude of simulated GPP. This parameter also contributes substantially $(\sim 4 \%)$ to the uncertainty in simulated yield. The other parameter contributing substantially $(\sim 7 \%)$ to this uncertainty is the main slope parameter $(b)$, which is the principal control over the yield attained for a given biomass.

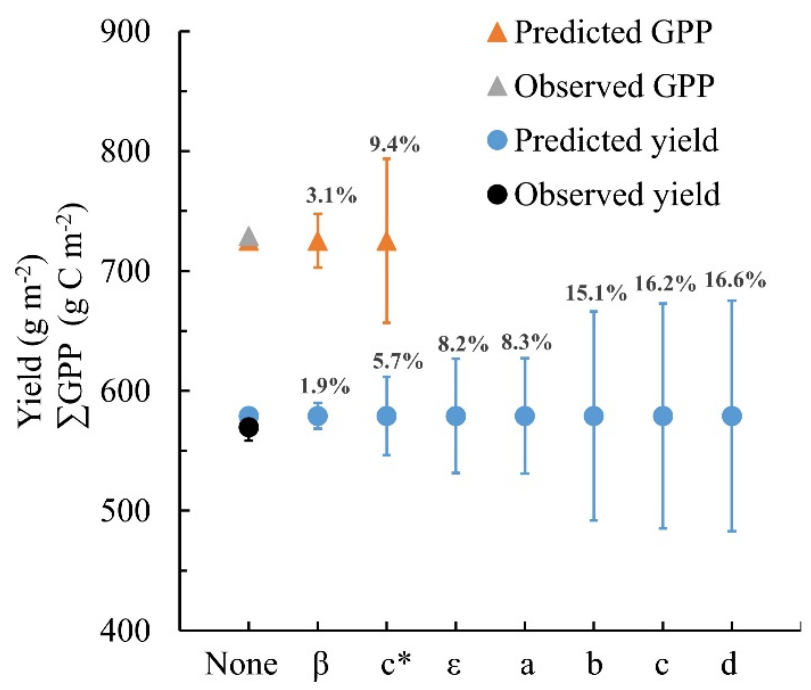

Figure 10: The impact of parameter uncertainty on the prediction of GPP accumulation and

yield. YuCheng 2005 was selected as a case study. Triangles represent GPP and dots represent yield.

407 The $x$-axis represents the progressive inclusion of $\pm 10 \%$ uncertainty in successive parameters, 408 indicated by their symbols.

\subsection{Model extension and application}

\subsubsection{Testing the phenology scheme}

The phenology scheme was shown to reproduce seasonal patterns of LAI today (Fig. 11) 412 reasonably well $\left(\mathrm{R}^{2}=0.84\right)$. 


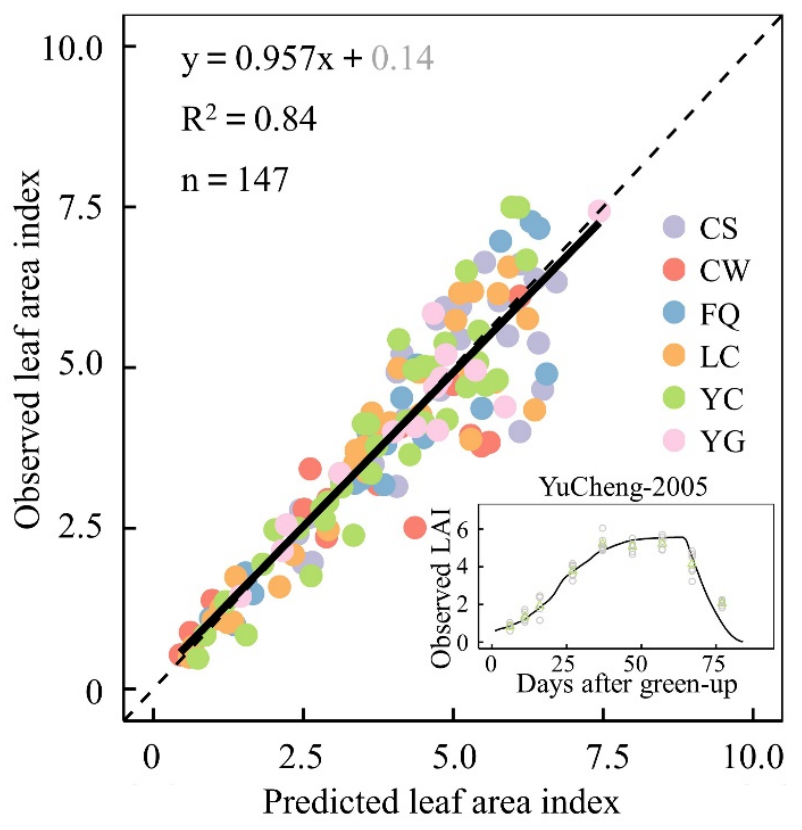

415 scheme. The inset shows the observed (circles, green is mean value) and predicted (line) seasonal time 416 course of LAI at the YuCheng site in 2005. The grey number is not significant.

\section{$417 \quad$ 3.5.2 The relationship between leaf biomass and accumulated GPP}

A strong linear relationship $(r=0.94)$ was found between leaf biomass and accumulated GPP, 419 allowing us to estimate $\eta=0.32$ (Fig. 12) and thereby solve equation (10) for mean LAI over growth 420 phase.

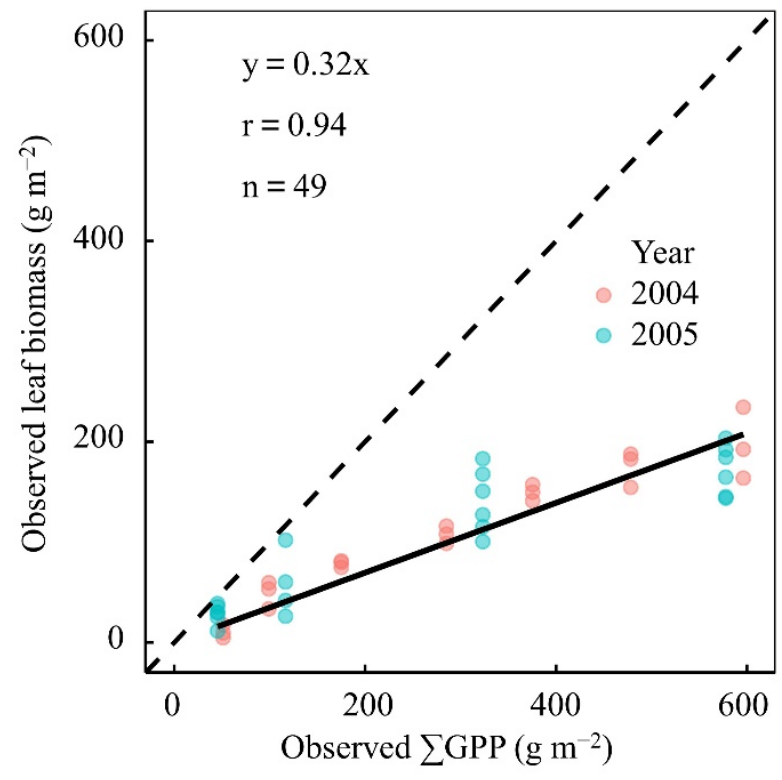


Figure 12: The proportion of gross primary production (GPP) allocated to leaves. The data are observations during the wheat growth phase in 2004 and 2005 at YuCheng. All values were accumulated from green-up to measurement time.

Projections of changing LAI as a function of $\mathrm{CO}_{2}$ concentration are shown in Figure $14 \mathrm{~b}$ and Figure S4. Modelled LAI increases in response to increasing $\mathrm{CO}_{2}$, but when the effect of increasing LAI on LMA is considered, the increase is much smaller and reaches a maximum at around $600 \mathrm{ppm}$. This behaviour is consistent with the maximum yield enhancement indicated by raised $\mathrm{CO}_{2}$ experiments, as summarized in the meta-analysis by Broberg et al. (2019).

\subsubsection{Sensitivity analyses}

Modelled grain yields increase with rising $\mathrm{CO}_{2}$ concentration, and decrease with increasing temperature, when other variables are kept fixed (Fig. 13). Higher temperature shortens the growing season (Fig. 14d) leading to a reduction in total absorbed light. In addition, the response of modelled LUE to rising temperature follows a unimodal curve (see Fig. 14c) such that increasing temperature above the optimum reduces GPP (Long, 1991). Lower GPP means lower yield. On the other hand, rising $\mathrm{CO}_{2}$ monotonically increases LUE, GPP and yield; and rising GPP leads to rising LAI, amplifying this effect. But the net effect of $\mathrm{CO}_{2}$ is limited by an increase in LMA.

For these scenarios and sites, the modelled positive effect of rising $\mathrm{CO}_{2}$ concentration on yield was greater than the negative effect of increasing temperature. However, the modelled reductions in yield caused by rising temperature differed among the sites (Fig. 13). Modelled wheat yields in warmer regions today, like YG and CS, are more sensitive to warming than cooler regions such as LC. 


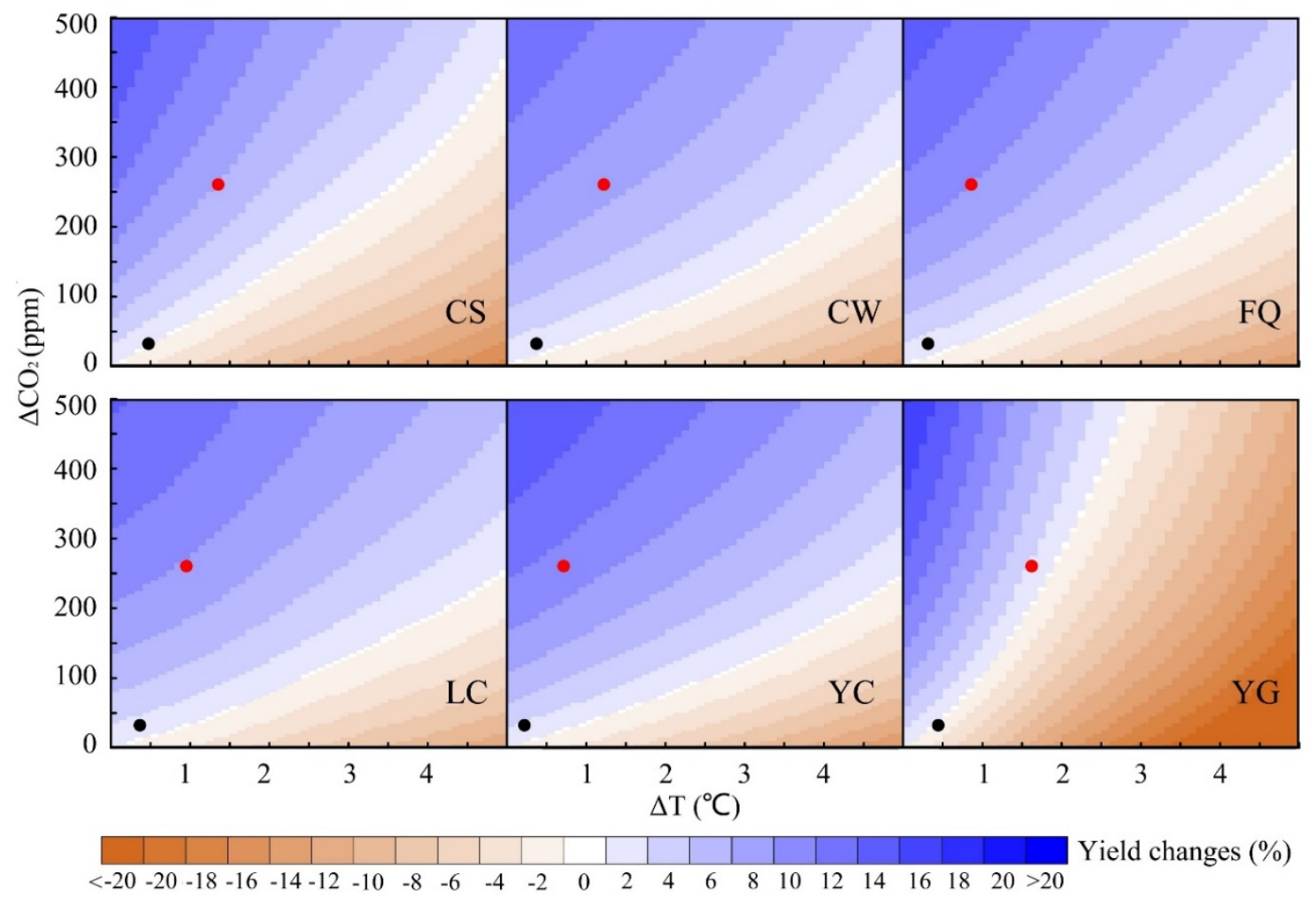

Figure 13: The response of predicted yield to rising $\mathrm{CO}_{2}$ and increasing temperature at six

444 sites. Dots mean increasing on temperature and mean rising on $\mathrm{CO}_{2}$ concentration in the last decade 445 (2090-2099) comparing with the first decade (2006-2015) under two future scenarios (RCP2.6, the 446 black dot, and RCP6.0, the red dot). The temperature is the mean value over growing season.
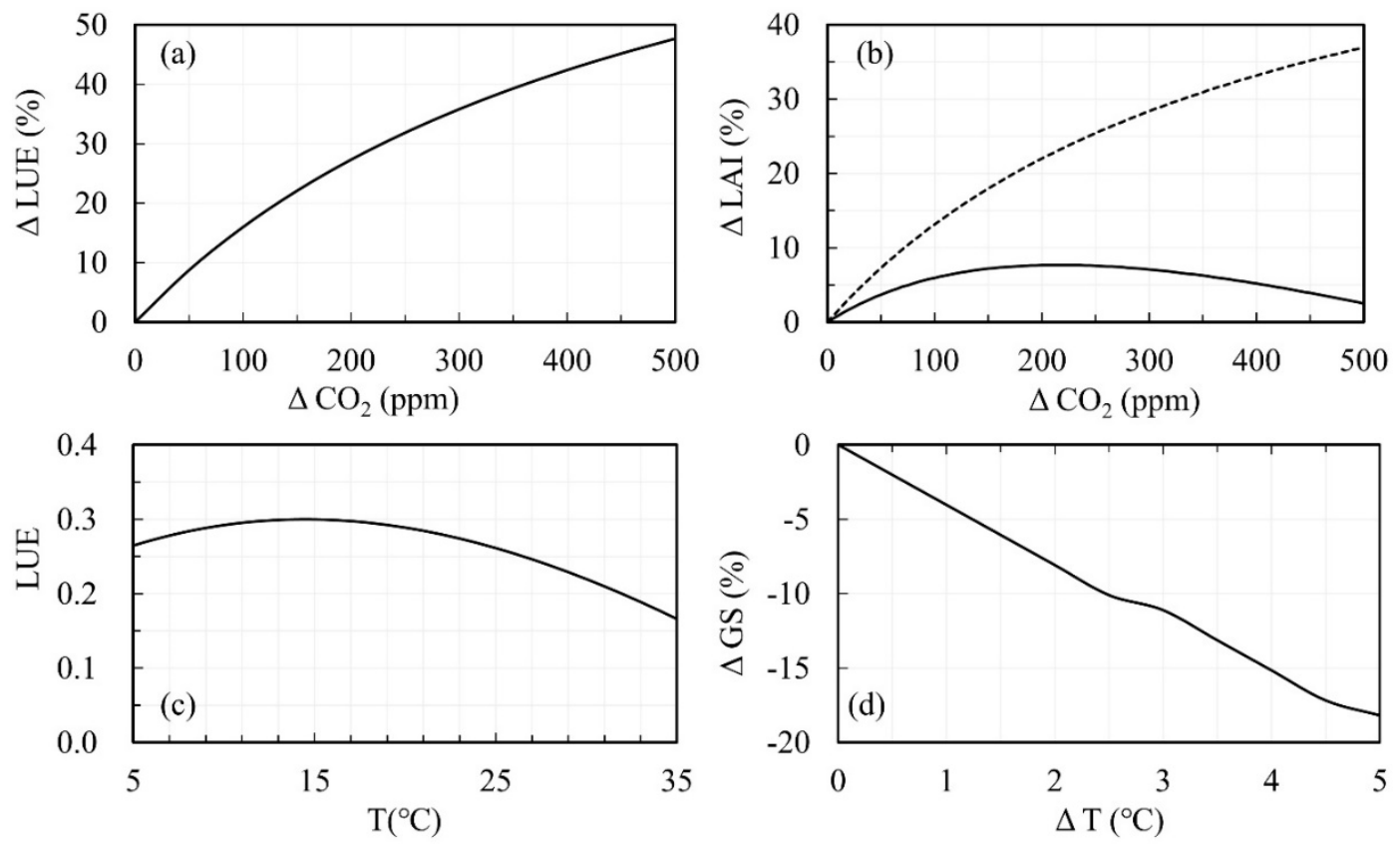

season length (GS) to $\mathrm{CO}_{2}$ concentration and temperature (T). Using the climate and $\mathrm{CO}_{2}$ measurements from YuCheng 2005 as a baseline condition. (a) The response of LUE change to $\mathrm{CO}_{2}$ increment. (b) The response of LAI change to $\mathrm{CO}_{2}$ increment. Solid line includes the effect of $\mathrm{CO}_{2}$ on

452 LMA; dash line excludes this effect. (c) The response of LUE to temperature. (d) The response of 453 changes in growing season length to temperature increment.

\subsubsection{Comparison with future scenario runs by other crop models}

We compared future scenarios with the PC model to ISIMIP2b model runs performed with the same scenarios using complex crop models. PC and LPJmL simulated contemporary yields reasonably well across all the sites, but the PEPIC and GEPIC models showed unrealistically low yields except at site CS. PC showed an increase in wheat yield $\sim 6.6 \%$ in the RCP2.6 and $\sim 15.1 \%$ in the RCP6.0 simulations by the end of the $21^{\text {st }}$ century (Fig. 15). Although the different crop models predict different absolute magnitudes of wheat yields, the trend and the interannual variations are similar among all models showed increases in wheat yield at individual sites over the $21^{\text {st }}$ century, with the exception of the PEPIC model at the YG site.
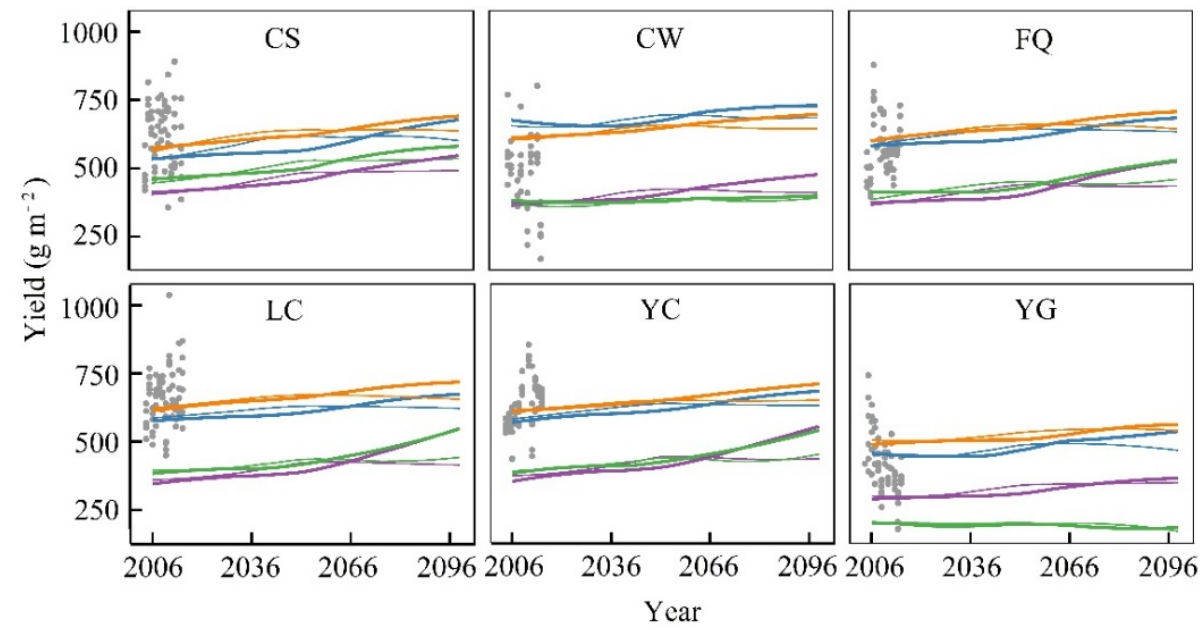

- Observation

- PC model-RCP6.0

PC model-RCP2.6

- LPJmL-RCP6.0

LPJmL-RCP2.6

- PEPIC-RCP6.0

- PEPIC-RCP2.6

- GEPIC-RCP6.0 
Figure 15: Comparison of different crop models: future scenarios at six sites. The climate

data to drive the crop models were derived from the MIROC5 climate model. Lines represent modelled interannual yield trends; Points represent measured yields.

\section{Discussion}

The P model has been extensively tested against GPP derived from flux measurements in natural vegetation (Stocker et al., 2019; Wang et al., 2017) and has also been shown to perform well in simulating the GPP of croplands (Balzarolo et al., 2018). The present study has confirmed that the P model can predict the GPP of irrigated and fertilized wheat crops in China (Fig. 3); that above-ground crop biomass can be modelled as a fraction of accumulated GPP (Fig. 4); and that yield can be modelled as a saturating function of $\mathrm{AB}$ (Fig. 5). Further extensions and tests of the model in a wider range of environmental and economic settings will be needed to allow application to model wheat crops under water and/or nutrient stresses (which are expected to result in different relationships among GPP, AB and yield), or in a wider range of climates.

The ratio of above-ground biomass production to GPP is typically 0.41 (natural) to 0.53 (managed) for forests, $\sim 0.2$ for natural grasslands and 0.6 to 0.7 for managed grasslands (Campioli et al., 2015). Values of this ratio, up to $\sim 0.8$, have been found for intensively managed crops (Campioli et al., 2015; Chen et al., 2018; Huang et al., 2018). The value of 0.72 estimated in our study is in the upper part of the expected range. This is not unreasonable. As an annual crop, wheat does not require strong roots for support. In addition, the study sites are irrigated (to eliminate water stress) and fertilized (to reduce or eliminate nutrient stress), so the below-ground carbon allocation needed to acquire nutrients and water is minimal. Modern varieties of wheat are highly efficient in converting GPP to biomass because selective breeding has aimed to increase the GPP allocation to biomass, and ultimately to grain.

Most crop models assume that grain yield is a fixed proportion of above-ground or total biomass, the so-called harvest index (HI) (Donald, 1962; Hay, 1995). However, the grain yield data analysed 
here follow a saturation function with $\mathrm{AB}$ (Fig. 5), so that $\mathrm{HI}$ declines with increasing $\mathrm{AB}$. The level of $\mathrm{AB}$ at which saturation occurs is largely determined by the wheat variety (Fig. 6 and Fig. S1). The maximum yield given by $(a \cdot N+b)$ in equation (5) is influenced by the wheat variety and the amount of nitrogen added. The actual yield is also determined by the amount of biomass accumulated and, therefore, by the GPP during the growing season - which depends on $\mathrm{CO}_{2}$, climate, canopy development and incident PPFD. The negative intercept $(d)$ quantifies the requirement for a certain minimum biomass accumulation before any carbon is allocated to seeds. When a linear regression was fitted instead of a saturating function, the estimate of $d$ became positive, which is biologically impossible as it suggests a positive yield when $\mathrm{AB}$ is zero (Fig. S2).

It follows from this simple empirical representation of the experimental data that improving grain yield is not simply a case of adding more fertilizer (which also comes with significant monetary and environmental costs). Moreover, yields will also not automatically increase in proportion to the effect of $\mathrm{CO}_{2}$ on photosynthesis, because the saturating nature of this relationship implies a "diminishing return" on increases in $\mathrm{AB}$. The differences among varieties are potentially important here. They suggest that a key target for crop improvement should be the ability of the plants to allocate more carbon to grain as $\mathrm{AB}$ increases, and thereby to profit from higher $\mathrm{CO}_{2}$ levels.

Both the current level and the trend in yield over the $21^{\text {st }}$ century simulated by the PC model are similar to that shown by the LPJmL model (Fig. 15). This similarity is probably due to the fact that the LPJ component of LPJmL, is also, ultimately, based on the standard model of photosynthesis and the acclimation of $V_{\mathrm{cmax}}$ - the latter process now supported by a wealth of evidence (Smith et al., 2019). However, the PC model is simpler, has fewer parameters and is more transparent, with major advantages both for the credibility of the results and the ease with which uncertainties can be quantified and traced to their source.

Quantification of prediction uncertainties in complex models requires extensive computation to estimate the sensitivity to their many parameters. In contrast, the PC model consists of a single central 
equation (1a), which can readily be differentiated with respect to its (far fewer) parameters. This process allows uncertainties to be attached to predictions without excessive computational demands and allows the major sources of uncertainty to be pinpointed. We have shown that the parameter $c^{*}$, related to the metabolic costs of maintaining electron transport capacity, and parameter $b$, related to the potential maximum yield, accounts for a large fraction of the prediction uncertainty (Fig. 10) indicating the importance of further work to improve these aspects of the model.

Studies have suggested that rising temperatures could greatly reduce the grain yield of wheat (Asseng et al., 2014; Asseng et al., 2011; Zhao et al., 2017; Zhao et al., 2016), because of the shortened growing season. However, many studies have neglected the effects of rising $\mathrm{CO}_{2}$ on $\mathrm{C}_{3}$ photosynthesis, which has the potential to mitigate the impact of rising temperatures on production by improving LUE, particularly as the temperature optimum shifts to higher temperatures with rising $\mathrm{CO}_{2}$. The effects of elevated $\mathrm{CO}_{2}$ have been shown by Free Air Carbon dioxide Enrichment (FACE) experiments, with positive impacts on wheat yields and net assimilation rates (Broberg et al., 2019).

The primary mechanism by which increasing $\mathrm{CO}_{2}$ increases GPP is through the improvement of LUE. This mechanism is amplified by the positive feedback by which increased GPP allows greater LAI, which in turn implies greater light absorption and GPP. On the other hand, LMA increases with $\mathrm{CO}_{2}$, resulting in a diminished response and, according to our model, a peak of the positive response of LAI to $\mathrm{CO}_{2}$ above $\sim 600 \mathrm{ppm}$ (Fig. $14 \mathrm{~b}$ and Fig. S4). However, we see no peak in the positive response of yield to $\mathrm{CO}_{2}$. This appears to be because $f \mathrm{APAR}$ is comparatively insensitive to changes in LAI at the high end. However, according to our simulations, a positive but saturating response of yield and LUE to $\mathrm{CO}_{2}$ are found at high $\mathrm{CO}_{2}$ levels (Fig. 13 and Fig. 14a). This appears to be inconsistent with the yield response shown in the meta-analysis of enhanced $\mathrm{CO}_{2}$ experiments by Broberg et al. (2019). However, the response shown in that paper is small, solely derived from chamber rather than FACE experiments, and seems to reflect the reduced sensitivity of higher yield wheat varieties to $\mathrm{CO}_{2}$ changes. 
The magnitude of yield enhancement simulated by our model is consistent with the findings of

540 Broberg et al. (2019) for the mid-range of wheat yields. Field warming experiments, summarised in 541 Zhao et al. (2016), show negative responses of yield to warming of between 0.5 to $3.0^{\circ} \mathrm{C}$ at individual 542 sites in northwestern and northern China, with an average response of $-4.4 \%$ per ${ }^{\circ} \mathrm{C}$ in northwestern 543 China to $-2.8 \%$ per ${ }^{\circ} \mathrm{C}$ in northern China. Across our study sites (which are in the same region), we 544 predict a net negative response to increased temperature of between -2.3 and -5.7 per ${ }^{\circ} \mathrm{C}$. This 545 response is caused by the reduction in the length of the growing season and the negative impact of 546 temperature on LUE. The modelled response of yield to combinations of raised $\mathrm{CO}_{2}$ and temperature, 547 as shown by sensitivity analysis, reflects a combination of net positive effects of $\mathrm{CO}_{2}$ and net negative 548 effects of rising temperature. Scenario runs show that, under the scenarios tested, the positive effects 549 of $\mathrm{CO}_{2}$ on yield however outweigh the negative effects of temperature, consistent with the findings of 550 other crop models for China (Liu et al., 2019). Warmer regions are more sensitive to warming than 551 cooler regions (also consistent with Liu et al. (2019)), indicating that wheat production in warmer 552 regions of China will be more challenged by climate change.

\section{Conclusions}

The yield of irrigated and fertilized wheat crops at research sites across the wheat-growing region of China was simulated successfully using a parsimonious model based on a combination of first557 principles theoretical considerations governing GPP with empirical analyses of the relationships amongst GPP, AB and yield. The model reproduced the general magnitude and patterns of interannual variability in both $\mathrm{AB}$ and yield. When driven by future climate and $\mathrm{CO}_{2}$ scenarios, it produced results similar to those of the most credible of the more complex crop models.

The model also provided insights into how wheat yields may respond to global environmental change. The effect of rising $\mathrm{CO}_{2}$ on photosynthesis does not imply proportionately increased yield. 
$600 \mathrm{ppm}$. The model also predicted a negative effect of warming on wheat yields. Sensitivity analysis showed this negative effect to be stronger in regions with warmer climates today. Nonetheless, in common with other crop models, the simulations indicated an increase of $\sim 6.6 \%$ in wheat yields under the RCP2.6 and $\sim 15.1 \%$ under the RCP6.0 scenarios of future $\mathrm{CO}_{2}$ and climate.

\section{Acknowledgements}

The authors thank Huimin Lei and Dawen Yang for providing the data at the WeiShan site, and Yiqi Luo, Kun Yang, Chaoqing Yu and Zaichun Zhu for their comments on the analysis. This research was supported by the National Key R\&D Program of China (no. 2018YFA0605400), National Natural Science Foundation of China (no. 31600388). ICP and SPH acknowledge support from the High-End Foreign Expert programme of the China State Administration of Foreign Expert Affairs (no. 161207002). SPH acknowledges funding from the European Research Council (ERC) for "GC2.0: Unlocking the past for a clearer future". This research contributes to the AXA Chair Programme in Biosphere and Climate Impacts and the Imperial College initiative on Grand Challenges in Ecosystems and the Environment (ICP). ICP also acknowledges funding from the ERC, under the European Union's Horizon 2020 research and innovation programme (grant agreement No: 787203 REALM).

\section{References}

Ainsworth, E.A. and Rogers, A., 2007. The response of photosynthesis and stomatal conductance to rising $\mathrm{CO}_{2}$ : mechanisms and environmental interactions. Plant Cell Environ, 30(3): 258-270.

Asseng, S. et al., 2014. Rising temperatures reduce global wheat production. Nature Climate Change, 5(2): $143-147$.

Asseng, S., Foster, I. and Turner, N.C., 2011. The impact of temperature variability on wheat yields. Global Change Biology, 17(2): 997-1012.

Asseng, S. et al., 2004. Simulated wheat growth affected by rising temperature, increased water deficit and elevated atmospheric $\mathrm{CO}_{2}$. Field Crops Research, 85(2-3): 85-102.

Balzarolo, M. et al., 2018. TerrA-P: Development and validation of a global GPP/NPP model using MERIS and Sentinel3 data. Validation report, Available at https://terra-p.vito.be/about/deliverables.

Bernacchi, C.J., Pimentel, C. and Long, S.P., 2003. In vivo temperature response functions of parameters required to model RuBP-limited photosynthesis. Plant Cell Environ, 26(9): 1419-1430.

Bernacchi, C.J., Singsaas, E.L., Pimentel, C., Portis, A.R. and Long, S.P., 2001. Improved temperature response functions for models of Rubisco-limited photosynthesis. Plant Cell Environ, 24(2): 253-259.

Betts, A., Jia, P.W. and Dodson, J., 2014. The origins of wheat in China and potential pathways for its introduction: A review. Quaternary International, 348: 158-168.

Blanc, E., 2017. Statistical emulators of maize, rice, soybean and wheat yields from global gridded crop models. Agricultural and Forest Meteorology, 236: 145-161.

Bondeau, A. et al., 2007. Modelling the role of agriculture for the 20th century global terrestrial carbon balance. Global Change Biology, 13(3): 679-706. 
Boylan, M., 2016. What Have We Learned From 15 Years of Supporting the Development of Innovative Teaching Technology? Soc Sci Comput Rev, 22(4): 405-425.

Broberg, M.C., Hogy, P., Feng, Z.Z. and Pleijel, H., 2019. Effects of Elevated $\mathrm{CO}_{2}$ on Wheat Yield: Non-Linear Response and Relation to Site Productivity. Agronomy-Basel, 9(5): 243.

Brooking, I.R., 1996. Temperature response of vernalization in wheat: A developmental analysis. Ann Bot-London, 78(4): 507-512.

Campbell, G.S. and Norman, J.M., 2012. An introduction to environmental biophysics. Springer Science \& Business Media.

Campioli, M. et al., 2015. Biomass production efficiency controlled by management in temperate and boreal ecosystems. Nature Geoscience, 8(11): 843-846.

Cao, L.J. et al., 2017. Climatic warming in China during 1901-2015 based on an extended dataset of instrumental temperature records. Environmental Research Letters, 12(6).

Challinor, A.J. and Wheeler, T.R., 2008. Crop yield reduction in the tropics under climate change: Processes and uncertainties. Agricultural and Forest Meteorology, 148(3): 343-356.

Chen, Z., Yu, G.R. and Wang, Q.F., 2018. Ecosystem carbon use efficiency in China: Variation and influence factors. Ecological Indicators, 90: 316-323.

Collins, M. et al., 2014. Long-term Climate Change: Projections, Commitments and Irreversibility. Climate Change 2013: The Physical Science Basis: 1029-1136.

Donald, C., 1962. In search of yield. J. Aust. Inst. Agric. Sci., 28: 171-178.

Elliott, J. et al., 2015. The Global Gridded Crop Model Intercomparison: data and modeling protocols for Phase 1 (v1.0). Geoscientific Model Development, 8(2): 261-277.

FAOSTAT, 2018. FAOSTAT statistical database, Available at http://www.fao.org/faostat/en/\#data/QC.

Farquhar, G.D., von Caemmerer, S. and Berry, J.A., 1980. A biochemical model of photosynthetic $\mathrm{CO}_{2}$ assimilation in leaves of $\mathrm{C}_{3}$ species. Planta, 149(1): 78-90.

Franklin, O. et al., 2017. Using natural selection and optimization for smarter vegetation models - challenges and opportunities, Egu General Assembly Conference.

Gerbaud, A. and Andre, M., 1980. Effect of $\mathrm{CO}_{2}, \mathrm{O}_{2}$, and Light on Photosynthesis and Photorespiration in Wheat. Plant Physiol, 66(6): 1032-6.

Hay, R.K.M., 1995. Harvest Index - a Review of Its Use in Plant-Breeding and Crop Physiology. Annals of Applied Biology, 126(1): 197-216.

He, L. et al., 2015. Impacts of recent climate warming, cultivar changes, and crop management on winter wheat phenology across the Loess Plateau of China. Agricultural and Forest Meteorology, 200: 135-143.

Huang, J.X. et al., 2016. Assimilating a synthetic Kalman filter leaf area index series into the WOFOST model to improve regional winter wheat yield estimation. Agricultural and Forest Meteorology, 216: 188-202.

Huang, K. et al., 2018. Enhanced peak growth of global vegetation and its key mechanisms. Nat Ecol Evol, 2(12): 18971905.

Kirtman, B. et al., 2014. Near-term Climate Change: Projections and Predictability. Climate Change 2013: The Physical Science Basis: 953-1028.

Lawlor, D.W. and Mitchell, R.A.C., 1991. The Effects of Increasing $\mathrm{CO}_{2}$ on Crop Photosynthesis and Productivity - a Review of Field Studies. Plant Cell Environ, 14(8): 807-818.

Lei, H.M. and Yang, D.W., 2010. Seasonal and interannual variations in carbon dioxide exchange over a cropland in the North China Plain. Global Change Biology, 16(11): 2944-2957.

Liu, B. et al., 2019. Global wheat production with 1.5 and 2.0 degrees C above pre-industrial warming. Global Change Biology, 25(4): 1428-1444.

Liu, J.G., Williams, J.R., Zehnder, A.J.B. and Yang, H., 2007. GEPIC - modelling wheat yield and crop water productivity with high resolution on a global scale. Agr Syst, 94(2): 478-493.

Liu, W.F. et al., 2016. Global investigation of impacts of PET methods on simulating crop-water relations for maize. Agricultural and Forest Meteorology, 221: 164-175.

Liu, Y.J. et al., 2018. Modelling the impacts of climate change and crop management on phenological trends of spring and winter wheat in China. Agricultural and Forest Meteorology, 248: 518-526.

Long, S.P., 1991. Modification of the Response of Photosynthetic Productivity to Rising Temperature by Atmospheric $\mathrm{CO}_{2}$ Concentrations - Has Its Importance Been Underestimated. Plant Cell Environ, 14(8): 729-739.

Maire, V. et al., 2012. The coordination of leaf photosynthesis links $\mathrm{C}$ and $\mathrm{N}$ fluxes in $\mathrm{C}_{3}$ plant species. PLoS One, 7(6): e38345.

Monsi, M., 1953. Uber den Lichtfaktor in den Pflanzen-gesellschaften und seine Bedeutung fur die Stoffproduktion. Jap. Journ. Bot., 14: 22-52.

Muller, C. and Robertson, R.D., 2014. Projecting future crop productivity for global economic modeling. Agricultural Economics, 45(1): 37-50.

Neitsch, S.L., Arnold, J.G., Kiniry, J.R. and Williams, J.R., 2011. Soil and water assessment tool theoretical documentation version 2009, Texas Water Resources Institute. 
Nelson, G.C. et al., 2014. Agriculture and climate change in global scenarios: why don't the models agree. Agricultural Economics, 45(1): 85-101.

Nielsen, D.C. and Halvorson, A.D., 1991. Nitrogen Fertility Influence on Water-Stress and Yield of Winter-Wheat. Agron J, 83(6): 1065-1070.

Ostberg, S., Schewe, J., Childers, K. and Frieler, K., 2018. Changes in crop yields and their variability at different levels of global warming. Earth System Dynamics, 9(2): 479-496.

Palosuo, T. et al., 2011. Simulation of winter wheat yield and its variability in different climates of Europe: A comparison of eight crop growth models. European Journal of Agronomy, 35(3): 103-114.

Pan, H.Z., Chen, Z.X., Ren, J.Q., Li, H. and Wu, S.R., 2019. Modeling winter wheat leaf area index and canopy water content with three different approaches using Sentinel-2 multispectral instrument data. IEEE Journal of Selected Topics in Applied Earth Observations and Remote Sensing, 12(2): 482-492.

Piao, S. et al., 2010. The impacts of climate change on water resources and agriculture in China. Nature, 467(7311): 4351.

Porter, J.R. and Gawith, M., 1999. Temperatures and the growth and development of wheat: a review. European Journal of Agronomy, 10(1): 23-36.

Porter, J.R. et al., 2014. Food Security and Food Production Systems. Climate Change 2014: Impacts, Adaptation, and Vulnerability, Pt A: Global and Sectoral Aspects: 485-533.

Prentice, I.C., Dong, N., Gleason, S.M., Maire, V. and Wright, I.J., 2014. Balancing the costs of carbon gain and water transport: testing a new theoretical framework for plant functional ecology. Ecol Lett, 17(1): 82-91.

Prentice, I.C., Liang, X., Medlyn, B.E. and Wang, Y.P., 2015. Reliable, robust and realistic: the three R's of nextgeneration land-surface modelling. Atmospheric Chemistry and Physics, 15(10): 5987-6005.

Prentice, I.C. and Thomas, R., 2018. Development and validation of a global GPP/NPP model using MERIS and Sentinel-3 data (TerrA-P) ATBD v2, Available at https://terra-p.vito.be/about/deliverables.

Qin, X.L. et al., 2015. Wheat yield improvements in China: Past trends and future directions. Field Crops Research, 177: 117-124.

Sage, R.F., Sharkey, T.D. and Seemann, J.R., 1989. Acclimation of Photosynthesis to Elevated $\mathrm{CO}_{2}$ in Five $\mathrm{C}_{3} \mathrm{Species}$ Plant Physiol, 89(2): 590-6.

Schaphoff, S. et al., 2018. LPJmL4-a dynamic global vegetation model with managed land - Part 1: Model description. Geoscientific Model Development, 11(4): 1343-1375.

Smith, N.G. et al., 2019. Global photosynthetic capacity is optimized to the environment. Ecol Lett, 22(3): 506-517.

Stocker, B.D. et al., 2019. P-model v1. 0: An optimality-based light use efficiency model for simulating ecosystem gross primary production. Geosci. Model Dev. Discuss, 37: 1-59.

Tao, F.L., Zhang, S.A. and Zhang, Z., 2012. Spatiotemporal changes of wheat phenology in China under the effects of temperature, day length and cultivar thermal characteristics. European Journal of Agronomy, 43: 201-212.

Thilakarathne, C.L. et al., 2013. Intraspecific variation in growth and yield response to elevated $\mathrm{CO}_{2}$ in wheat depends on the differences of leaf mass per unit area. Functional Plant Biology, 40(2): 185-194.

Wang, F.H. et al., 2009. Wheat cropping systems and technologies in China. Field Crops Research, 111(3): 181-188.

Wang, H. et al., 2017. Towards a universal model for carbon dioxide uptake by plants. Nat Plants, 3(9): 734-741.

Wu, J., Gao, X.J., Giorgi, F. and Chen, D.L., 2017. Changes of effective temperature and cold/hot days in late decades over China based on a high resolution gridded observation dataset. International Journal of Climatology, 37: 788-800.

Yu, C. et al., 2019. Managing nitrogen to restore water quality in China. Nature, 567(7749): 516-520.

Zhao, C. et al., 2017. Temperature increase reduces global yields of major crops in four independent estimates. Proc Natl Acad Sci U S A, 114(35): 9326-9331.

Zhao, C. et al., 2016. Field warming experiments shed light on the wheat yield response to temperature in China. Nat Commun, 7: 13530 . 